\title{
LOS VILLAGRANES DE HUICHAPAN Y LA VISITA DE IGNACIO RAYÓN
}

\section{LOS VILLAGRANES DE HUICHAPAN AND THE VISIT OF IGNACIO RAYON}

\author{
Carlos Herrejón Peredo \\ El Colegio de Michoacán \\ peredoch@gmail.com
}

\begin{abstract}
This article shows the complexity of the insurgent movement in Huichapan and its region during the predominance of the Villagrán family guerrillas; likewise, it considers the impact that Ignacio Rayón's visit as president of the Supreme National Governing Board had in that region. It ponders the distinct type of war that was carried out on one side by the Villagranes and the priest Manuel Correa and on the other by Ignacio Rayón, together with the problems that such visit entailed, which is characterized (both in the immediate and in the transcendent) by the commemorative celebrations that it implied.
\end{abstract}

Keywords: Ignacio Rayon, Supreme National Governing Board, Villagran, partisan, War of Independence.

\section{Resumen}

Este artículo muestra elementos de la complejidad del movimiento insurgente en Huichapan y su región durante el predomino de los guerrilleros de la familia Villagrán; asimismo, valora la incidencia que tuvo en esa región la visita de Ignacio Rayón como presidente de la Suprema Junta Nacional Gubernativa. Se busca ponderar el diverso tipo de guerra que llevaban a cabo por una parte los Villagranes, así como el cura Manuel Correa, y por otra, Ignacio Rayón, junto con la problemática que comportó tal visita, que se caracteriza tanto en lo inmediato como en lo trascendente, por las celebraciones conmemorativas que implicó.

Palabras clave: Ignacio Rayón, Suprema Junta Nacional Gubernativa, Villagrán, partisano, Guerra de Independencia. 


\section{Introducción}

Este artículo es un breve corte en el espacio y en el tiempo de la guerra insurgente. Va de Tlalpujahua a Huichapan, Nopala e Ixmiquilpan y poco más; el tiempo, principalmente de agosto a noviembre de 1812. El diverso tipo de guerra que encontramos en estos parámetros puede ponderarse a la luz de teorías e interpretaciones, comenzando con la figura del partisano tratado por Schmitt (2013), quien parte de la guerrilla que hizo el pueblo español contra el ejército francés invasor de 1808 a 1813. El partisano es el combatiente de esa guerrilla, cuyos rasgos principales son: guerra irregular, movilidad, rapidez, cambios bruscos de ataque y retirada, apego a la tierra e intensidad de compromiso político, que lo distingue del vil ladrón y atracador. El partisano entra en un círculo de terror y contraterror hasta la aniquilación total. Está conectado con la guerra civil (Schmitt, 2013: 23-25, 29, 32-34). Veremos hasta qué punto las guerrillas y los guerrilleros de Huichapan entran en esta categoría en contraposición con la guerra regular que promovía Ignacio Rayón, particularmente en su visita a la región. Ambas guerras, tanto la guerrilla de insurgentes de Huichapan como la de Rayón, que había iniciado a principios de 1811, forman parte de la prolongada guerra que, de acuerdo con Moisés Guzmán,

fue percibida por sus contemporáneos no sólo como un conflicto entre hermanos, sino también como una verdadera revolución, porque trastocó el orden social tradicional y fracturó la unidad política de la Monarquía [...] la guerra no mantuvo un mismo patrón de conducta en todos esos años que duró el conflicto; por el contrario, atravesó por distintas fases tanto en sus tácticas y estrategias de combate como en su naturaleza misma [...] Desde un inicio el enfrentamiento fue entendido como una guerra de independencia (Guzmán, 2007: 8-9).

Van Young enfatiza que los grupos subalternos rebelados en Nueva España a par- tir de 1810 tenían sus propios fines, distintos y aun opuestos a las metas de la dirigencia insurgente: entre otros, ahí están los guerrilleros de Huichapan (Van Young, 2006: 337-372). Sin embargo, tanto Guardino como Lempérière advierten que tal división no siempre se dio. El primero no comparte "la aguda división entre las motivaciones de la élite política para rebelarse y las motivaciones sociales que atribuyeron a los campesinos de la Nueva España" Archer, Hamnett, Tutino y Van Young (Guardino, 2001: 89-90). Por su parte, Lempérière considera que "políticamente hablando, es difícil sostener que los grupos subalternos sólo participaron en las guerras para desarrollar sus propios objetivos limitados, localistas, puramente sociales, opuesta a los proyectos de las élites" (2004: 35); da como razón que todo el clero involucrado en el conflicto formaba parte de la élite cultural tradicional en todos los niveles sociales. El señalamiento forma parte la propuesta de la misma autora consistente en rebasar "las disyuntivas esterilizantes entre revolución, guerra civil y guerra de independencia" (2004: 17), incluyendo la dimensión religiosa. De esta suerte destaca el carácter revolucionario de las guerras de independencia por su índole fundamentalmente legitimista, en cuanto que presentaron desde un principio las características de un proceso revolucionario: la soberanía cambió de manos, al asumir prerrogativas distintivas y exclusivas del monarca: declarar la guerra, levantar hombres para formar ejércitos, exigir recursos para financiar el conflicto, establecer relaciones diplomáticas; y por otra parte señala la violencia radical de la guerra civil (2004: 34).

Marco Antonio Landavazo, a su vez, da por sentado que se trataba de una guerra civil, en que la violencia, incluso extrema, se ejercía por ambos bandos de manera, a fin de cuentas, indiscriminada, con tal de lograr el triunfo de cada causa, no obstante los controles que introducían (2005: 833-865).

A pesar de lo dicho, Tomás Pérez Vejo defiende que el conflicto bélico que marca el nacimiento de la modernidad política en los territorios de la Monarquía Católica no 
fue una confrontación internacional -españoles contra americanos, contra mexicanos, argentinos, etcétera- sino una guerra civil, americanos contra americanos, lo que explicaría que esta especie de guerra fundacional no sólo no fortaleciese el Estado sino que más bien lo debilitase (2012: 62). Uno de sus argumentos principales reposa sobre el hecho que los ejércitos realistas en su casi mayoría estaban compuestos por criollos, indios y castas de Nueva España; incluso aun después de la llegada de tropas expedicionarias, las novohispanas siguieron siendo gran mayoría. Sin embargo, no se explica suficientemente que las planas superiores del ejército, el tenientazgo general y el generalato, estaban reservadas para los peninsulares; a pesar de que algunos criollos con mucho esfuerzo apenas llegaban a coroneles, teniendo mayores méritos que peninsulares advenedizos. En cambio, dentro de la insurgencia el ascenso era dable, ya con los requisitos de Morelos, ya con la prodigalidad de Rayón, como veremos en nuestro caso. Es verdad que la guerra de independencia no fue un conflicto internacional en el sentido de nación contra nación, porque precisamente se trataba de lograr la categoría de Estado nación, luchando contra los representantes de la nación dominadora. Además, el odio al gachupín, justificado o no, marcó la primera insurgencia y entra en el propósito de independencia (Landavazo, 2009: 195-225). Habrá que tomar en cuenta la observación de Lemperiérère sobre disyuntivas esterilizantes: la guerra de independencia también fue guerra civil y revolución.

Las interpretaciones enunciadas ayudarán a reflexionar sobre los datos duros o empíricos, según vayamos avanzando en la exposición. Asimismo, en su momento daré cuenta de conceptos que enmarquen la celebración conmemorativa organizada por Rayón en Huichapan.

La investigación se llevó a cabo en fondos del Archivo General de la Nación y en la Biblioteca Nacional; en cuanto a impresos, privilegié el Prontuario de insurgentes, el Diario de Rayón, el periodismo insurgente y el realista, y los clásicos de la época. Visité varios lugares de la región y participé en celebraciones. Punto relevante en esta heurística fue utilizar una metodología que contrastara las fuentes realistas y las insurgentes sobre los hechos que narraban y valoraban, así como plasmar en mapas territorios y rutas. Dentro de la prensa insurgente hube de interrelacionar al detalle fechas y lugares, a fin de resolver contradicciones de la historiografía.

\section{Huichapan: escasez de agua y escándalos de una familia}

Por la región de Huichapan surcaban caminos entre Querétaro y la Ciudad de México. Era comarca de conexión o engrane, entre el centro de Nueva España y el Bajío de la insurgencia. Las raíces de este movimiento en Huichapan y su comarca se remontan a varios agravios padecidos a partir de los últimos decenios del siglo XVIII. Primero, un excesivo control del comercio de las telas de algodón que se hilaban en aquellos lugares: no había obrajes, pero se contaban algo más de 102 telares que funcionaban recibiendo el algodón de algunos europeos y entregándoles la tela a cambio de magras cantidades. Se les impedía que concurrieran directamente a su comercio. Segundo, el uso y control del agua. Tratándose de región escasa en este recurso, el agravio fue más sensible y general. Un benefactor del poblado, Manuel González, había financiado represa y embalse para uso público. Mas una vez fallecido, la familia de Manuel de la Paz se apoderó de la represa para beneficio exclusivo del riego de sus trigales. Otro abusivo, Antonio García, desviaba las corrientes que alimentaban el embalse para llevarlas a regar sus hortalizas. La falta de agua fue resentida principalmente por los indios y los dedicados a la arriería, entre ellos los Villagranes. Las protestas llegaron a la capital y el gobierno virreinal determinó a favor del bien común, mas no sabemos el cumplimiento efectivo (Hamnett, 1990: 163164). 
Los agravios se juntaron en 1809 con una sequía que provocó la escasez de maíz ese año y el siguiente en la jurisdicción de Huichapan, y sin duda, más allá. La carestía era aprovechada por comerciantes que podían surtirse de otras tierras. De tal suerte, el subdelegado informaba no sin angustia ( $A G N$, 1809: caja 578, exp. 3).

Hubo además dos escándalos en Huichapan previos a la insurrección, ambos protagonizados por miembros de la familia Villagrán. El primero ocurrió en agosto de 1809. Se trataba de José María, subteniente de la primera compañía de milicias de Huichapan, correspondiente a Tula, cuyo capitán era su tío, Julián Villagrán, padre de otro José María, homónimo del subteniente, apodado El Chito. Sucedió que el primer José María enamoró a una mujer casada, Regina Peimbert, y la hizo su amante, pues el marido pasaba temporadas fuera. Temiendo el subdelegado Juan Cortés y Olarte, así como el cura Manuel Toral, que una vez enterado el marido hubiera consecuencias que lamentar, habló el primero con el padre del subteniente, para que retrajera a su hijo de semejante conducta. Resultó contraproducente, pues José María más bien hizo gala de su adulterio y la emprendió contra el cura y el subdelegado: juntamente con su primo homónimo, El Chito, y otro, Juan Paniagua, intimidaron al cura echándole el caballo encima, y al subdelegado le tiraron un lazo a los pies, arrojándolo al suelo. Al día siguiente el subdelegado mandó llamar al alguacil para que aprehendiese a los facinerosos, pero éste le hizo ver que la familia de los Villagranes era extensa y tenían costumbre de juntarse todos y salir a defender a quien fuera de ellos en cualquier atentado o delito que cometiera.

Hubiera el subdelegado acudido al capitán de milicias, Julián Villagrán, pero como se mencionó, era tío del subteniente y padre de uno de los cómplices. Incluso sus exhortaciones eran que para ser buenos militares han de ser borrachos, enamorados y valientes.

De tal suerte el subteniente, sus cómplices y otros se mantenían dando mil escándalos, en cuadrilla de siete u ocho, cantando... mofando y escarneciendo la jurisdicción real.

Para alivio del subdelegado Cortés, llegó por entonces a Huichapan el capitán de infantería Bernardo de Orta, comisionado para la organización de compañías de ejército. De acuerdo con él, Juan Cortés elevó representaciones al virrey arzobispo Francisco Xavier de Lizana el 16 y el 17 de septiembre de 1809, pidiéndole su intervención. Éste consultó con Miguel Bataller, quien propuso que Orta se instruyera de los hechos y fuera auxiliado de la tropa necesaria para tomar la pronta providencia que las circunstancias demandaren. El 25 de septiembre asentía el virrey con ese parecer disponiendo que Orta averiguara los excesos cometidos y contara con los auxilios necesarios para reducir al orden al subteniente Villagrán y demás coludidos. En consecuencia, tanto Orta como el subdelegado Cortés iniciaron la instrucción de expedientes. Pero no los terminaron, porque el subteniente José María Villagrán y varios de los principales implicados ocurrieron ante el subdelegado, "detestando sus errores, haciendo las más sumisas protestas de su enmienda, hechos sus ojos un torrente de lágrimas y hasta cometer el exceso de arrojarse a mis pies, y queriendo besarlos e implorando, que como padre los mirase con piedad y que no los perdiese" (AGN, 1809: caja 5754, exp. 49). El subdelegado se conmovió y perdonó por su parte con la advertencia que sólo el virrey podría absolver del delito público. Informado el arzobispo virrey, resolvió el 28 de octubre, en el supuesto de verdadero arrepentimiento, que se diera por concluida la causa, sin mayor castigo, "haciendo a los culpados los apercibimientos correspondientes" (AGN, 1809: caja 5754, exp. 49).

El segundo escándalo, de mayores consecuencias, fue protagonizado por el otro José María Villagrán, El Chito, hijo de Julián y de María Anastasia Mejía, con quien Julián tuvo al menos otro hijo y seis hijas (García, 1910: 454). Padre e hijo eran de carácter violento y se embriagaban de vez en cuando. Pugnaban además por un mayor ascenso socioeconómico personal al igual que otros 
criollos e indios, con quienes compartían intereses y agravios. El 20 de septiembre de 1810 Chito, que trabajaba como empleado en la inmediata hacienda El Minto, en altercado mató a cuchilladas a su propietario, Antonio Chávez Nava, con cuya esposa, María Trinidad Uribe, Chito tenía devaneos amorosos. Se convirtió, pues, en un delincuente (Van Young, 2006: 340-341).

\section{Inicios de la insurgencia}

Mientras tanto, la insurrección de Hidalgo avanzaba por el Bajío y sin duda por diversos conductos llegó la noticia a Huichapan. Tal vez para entonces Julián Villagrán ya había sido invitado por Joaquín Arias, personaje de ambigüedad respecto a la insurgencia, a unirse a ella (Villaseñor y Villaseñor, 1963: 80-82), en la cual su hijo podría esquivar la pena de su asesinato. Sin embargo, es significativo que la adhesión de los Villagranes a la causa no se dio pronto o al menos no contaron con el apoyo mayoritario de Huichapan sino a fines de octubre de 1810. El propio Julián Villagrán reconocería que la Nación fue proclamada en Huichapan hasta el 28 de octubre. Antes no hay registro ahí de actividad insurgente de los Villagranes.'

Quizá los cálculos y la astucia de Julián le hacían dudar del partido que más le convendría. Lo que contribuyó a que saliera de indecisión y se pronunciara por la rebelión fue la actividad de Miguel Sánchez, comerciante y próspero labriego de Ixmiquilpan, conectado a la conspiración de Querétaro, quien viajaba por diversos rumbos y contaba con relaciones cerca de Salvatierra, en la hacienda de San Nicolás de los Agustinos.

Sánchez había logrado formar una tropa con peones de aquella hacienda y se presentó ante Hidalgo, quien le dio el grado de brigadier a su paso por Celaya el 20 o 21 de septiembre y probablemente lo comisionó

1 No encuentro base documental para las afirmaciones de Villaseñor y Villaseñor, 1963: 111) ni seguidores, en el sentido de que Julián Villagrán inmediatamente después del Grito de Dolores se hizo insurgente y junto con Miguel Sánchez se apoderaron de San Juan del Río. Los hechos narrados por el propio Villagrán dan otra visión. para que se aproximara a Querétaro con intento de tomarla. Al efecto, durante octubre Miguel Sánchez hizo de San Juan del Río su base de operaciones e incursionaba por la región. Es muy probable que entonces haya invitado por su cuenta a Julián Villagrán, a quien sin duda conocía, ya que Ixmiquilpan no queda lejos de Huichapan. A Julián hubo de impresionarle que alguien, a quien no consideraba de mayores dotes que él, ya tuviera grado de brigadier y encabezara multitudes.

Sánchez no pudo mantenerse en San Juan del Río a causa del frecuente paso de tropas del rey (Villaseñor y Villaseñor, 1963: 81); a cambio, una de sus partidas o el mismo Julián Villagrán, ya persuadido, capturaba el 28 o 29 de octubre al alcalde de Corte Juan Collado y otros funcionarios, que se dirigían de regreso a México. ${ }^{2}$ Collado llevaba los procesos de los capturados por la conspiración de Querétaro, como el de Epigmenio González. Se informó del hecho al brigadier Miguel Sánchez, quien estuvo de acuerdo en que Julián Villagrán fuera el subdelegado y comandante insurgente de Huichapan y su comarca.

Todo se festejó en Huichapan el 29 de octubre de 1810. El alcalde Collado, el subdelegado Cortés, el interventor Rodríguez, el teniente de corte Antonio Acuña, el cura Gil y otros tres fueron conducidos a prisión. Se tremolaron banderas: en una figuraba la Cruz y la frase "Viva Fernando VII", en la otra la imagen de la Virgen de Guadalupe. Por la tarde hubo recepción con Te Deum en la iglesia parroquial por parte de los clérigos bachiller Mariano Lezama, Ribera, Mariano Aguilar, vicario de Nopala, y José Antonio Magos, descendiente de cacique otomí y doctor en cánones. ${ }^{3}$

Por aquellos días Collado y acompañantes serían liberados. Mientras tanto, Sán-

2 Bustamante (1961: 74-75) atribuye a Sánchez la captura de Collado, en tanto que Alamán (1968: 258, 303) la asigna a Villagrán.

3 José Antonio Magos y García era originario de Huichapan, hijo de Marcelo Magos y María Inés Leal, y nieto del cacique Cayetano Magos. Obtuvo el doctorado en cánones el 3 de junio de 1804 (Fernández, 1963: 190; Hernández y Dávalos, 1877:109). En 1806 era consiliario en la Universidad (Carreño, 1963: 818, 819). 
chez se dirigía a Querétaro con intención de tomarla el 30 de octubre, pero fracasó, y para rehacerse se dirigió a Huichapan, donde entró el 1 de noviembre, siendo objeto de recepción solemne con otro Te Deum y cumplimiento de los principales vecinos, no sin disgusto de Villagrán, que fue colocado a la izquierda del brigadier. El Ilegado explicó las causas del fracasado ataque a Querétaro, pero planeó y dispuso campaña para tomar los reales mineros de Zimapán y Atotonilco el Chico, de tal manera reclutó gente y caballería de Huichapan, no sin disgusto y desconfianza de Villagrán, que vio la partida del contingente el 4 de noviembre con dirección primera hacia Alfajayucan.

Mas entonces se recibieron noticias de la proximidad de Calleja, decidido a entrar a degüello en Huichapan. La angustiada y desprotegida población civil hubo de abandonar la población y esconderse en los montes. Villagrán interpretó los acontecimientos como traición del brigadier Sánchez. De inmediato, con la gente que pudo convocar se dirigió a Alfajayucan para reclamar a Sánchez, éste contestó en tono de jácara y entonces Villagrán lo atravesó con su lanza. Huyeron sus inmediatos partidarios y Villagrán quedó como el principal cabecilla de la insurrección en la comarca.

El 15 de noviembre Villagrán, con ayuda de Cayetano y Mariano Anaya, lograría la captura de un convoy en Calpulalpa, en que resultó muerto el doctor Pedro Vélez, asesor de Calleja (Bustamante, 1961: 111; Alamán, 1968: 321); y tanto de esto como de todo lo anterior informaba a Miguel Hidalgo en larga carta el 19 del mismo mes, pidiéndole su aprobación y apoyo. Esta carta es la fuente principal en la narración hecha sobre los sucesos de la insurgencia incipiente en Huichapan (Miquel i Vergés, 1969: 533535, 603-604). De su lectura se advierte el escaso fundamento que tenía para calificar como traidor a Sánchez y más bien aflora su rivalidad. No sabemos la respuesta de $\mathrm{Hi}-$ dalgo, quien para esas fechas, luego de la derrota de Aculco y del segundo paso por Valladolid, se dirigía a Guadalajara. Por otra parte, los Villagranes auxiliaban a José Ma- riano Anaya en su intento de apoderarse de Jilotepec en aquellas primeras semanas de noviembre.

\section{La represión y el incremento de la causa: el tipo de guerra}

Tales actividades, más la captura del convoy, así como las noticias que daría sobre Huichapan el alcalde Collado, determinaron al gobierno virreinal a que José de la Cruz se encaminara con fuerte tropa a Huichapan, que ocupó el 21 de noviembre de 1810. Los Villagranes y muchos seguidores huyeron oportunamente al cerro de Ñastejé o La Muñeca. Cruz mandó ejecutar al menos a 14 tachados de rebeldía y a otros, del pueblo de San Francisco, los colgó en el camino; condenó a varios más a trabajos forzados y liberó a 13 españoles peninsulares que halló presos, uno moribundo. Además sacó 20 mil pesos "a los honrados vecinos de este pueblo”. Permanecería tres semanas en el lugar dictando medidas draconianas para toda la comarca: "he dado, o por mejor decir, repetido la orden de muertes e incendios; y por aquí ejecutaré lo mismo con cuantos acusados o sospechosos, no más, por manera que el fuego de la sedición quedará bien apagado a fuerza de castigos". Dos miembros de la familia Villagrán, uno hermano de Julián y otro sobrino, se le presentaron arrepintiéndose y pidiendo indulto para ellos y para Julián y El Chito. ${ }^{4}$ Cruz también se apersonó en el muy cercano pueblo de Nopala, cuyo párroco, el bachiller Manuel Correa, originario de Villa del Carbón, resultó sospechoso de infidencia, y por tal motivo fue enviado al arzobispo de México, donde se le retuvo, privándolo de su beneficio (Bustamante, 1961: 112; Alamán, 1968: 51-52; Van Young, 2006: 349-350; AGN, 1809: vol. 41, exp. 35, f. 63). Tales providencias resultaron contraproducentes a la causa virreinal, pues en Huichapan la insurgencia apenas tenía unos 20 días de haber iniciado, con signo de fidelidad a Fernando VII y a la religión.

\footnotetext{
4 José de la Cruz al Virrey, 29 de noviembre de 1810 y 1 de diciembre de 1810 (AGN, 1809: vol. 141, exp. 58, fs. 112r-113r; exp. 3, fs. 5r-7v).
} 
Por lo mismo, apenas se retiró Cruz de Huichapan la insurgencia resurgió ahí con mayor fuerza, pues a los agravios precedentes se sumaba ahora la represión brutal de José de la Cruz. Esto es parte de la explicación del rápido incremento de los grupos rebeldes en la región, en que destaca la confirmación de proseguir en la causa por parte de otros, como el huichapense y doctor en cánones ya mencionado, José Antonio Magos, quien desde el 24 de octubre en compañía de un párroco anterior de Huichapan habían pasado por Arnedo con objeto de unirse a Hidalgo; mas hubieron de retirarse a Xichú por la proximidad del ejército realista; de ahí Magos volvió a Huichapan y estuvo en la proclamación del día 28. Con el tiempo, Magos se convertiría en principal caudillo insurgente de la sierra Gorda (Hernández, 1877: 109; Miquel, 1969: 352).

Los Villagranes regresaron a Huichapan a mediados de diciembre de 1810. Se dice que la población a partir de fines de ese mes y hasta mediados de 1813 estuvo bajo control y extorsiones de los Villagranes, que ejecutaron a varios civiles españoles en la región (Van Young, 2006: 347-348). A principios de 1811 los Villagranes y sus gruesas partidas tenían "ocupada toda la distancia desde Querétaro a México”, según comunicaba Calleja a Bernardo Villamil (García, 1910: 104-105). Consiguientemente, el virrey dispuso que el teniente coronel Castro batiese a los Villagranes, cosa que logró en la hacienda de San Francisco para luego entrar a Huichapan el 10 de abril de 1811. Los insurgentes se escondieron en los cerros, para reunirse luego en Calpulalpan donde fueron dispersados el 19 de abril por el mayor Alonso, quien se reunió con Castro en Huichapan y de ahí partieron ambos el 3 de mayo hacia el cerro de La Magdalena, donde batieron de nueva cuenta a los rebeldes, comandados por El Chito Villagrán y Manuel Aldama; pasaron éstos por Cadereyta, donde varios indios de Tequisquiapan que se resistieron a unírseles fueron ejecutados. Ante la escalada represora, numerosas familias de insurgentes hubieron de refugiarse en el cerro del Moro, no lejos de San Juan del Río; pero hasta ese punto llegó el europeo Ildefonso de la Torre, quien las exterminó "haciendo una horrenda carnicería, sin distinción de sexo ni edad" (Alamán, 1968: 231, 260).

\section{El cura de Nopala, Manuel Correa, alineado con la Junta}

En septiembre de 1811 el comandante realista José Antonio Andrade se presentó en la región renovando las medidas represoras. En Nopala confiscó cuanto pudo y ejecutó a 18 jóvenes, pastores y leñeros, casi todos indios. Fue la gota que derramó el vaso para que el párroco José Manuel Correa se adhiriese militarmente a la insurrección. Había tenido noticia de ella desde el 30 de septiembre de 1810, gracias al arriero Cayetano Anaya. En un principio le pareció sedición reprobable, pero luego que Anaya volvió con otros parientes, trayendo mandato escrito de Miguel Hidalgo para propagar la insurgencia, Correa entró en confusión aumentada por el apoyo de clérigos a la causa en Huichapan el 28 de octubre ya mencionado. A partir de entonces simpatizó por la insurrección. Cuando José de la Cruz penetró en la región, en noviembre de 1810, llegó también a Nopala y mandó que Correa se presentase al arzobispo de México, quien lo retuvo privándolo de su beneficio parroquial. Pero en la primera oportunidad, hacia mediados de 1811, Correa se dirigió a su parroquia y fue entonces cuando ocurrió la matanza ordenada por Andrade (Bustamante, 1961: 415; Van Young, 2006: 521-524).

Para su levantamiento, el 24 de septiembre de 1811, el cura Correa contó con 400 hombres que puso a sus órdenes Miguel Arriaga; con ellos, aunque mal armados, y con otros 100 de El Chito Villagrán, Correa venció a Andrade el 26 de septiembre de 1811 en la Venta Hermosa; le hizo prisioneros, quitó armas y capturó 9000 carneros. Esto le valió que la Suprema Junta lo nombrase brigadier y comandante de Huichapan y Jilotepec, cosa que tal vez no agradó a Julián Villagrán, a pesar de la buena relación que tenían. A continuación, el párroco de Nopala venció a Antonio Columna en Villa 
del Carbón y enseguida capturó un convoy en Calpulalpan. El 2 de noviembre el mismo Andrade, reforzado por Castro y Michelena, obligó a Correa a esquivar el encuentro, episodio que el realista, habiendo entrado en Huichapan, pregonó como victoria, siendo que la tropa de Correa era de 55 hombres y sólo le mataron dos. Pero Correa lo engañó, pues provocó al enemigo desde Cadereyta, donde le infligió otra derrota el 11 de noviembre. Después acorraló al realista Columna y a sus hombres en Villa del Carbón, mas no penetró en ella, porque siendo su tierra natal, Correa tenía ahí a sus parientes. Coronó Correa esta primera fase de su actividad insurgente con la captura de otro convoy en que iba el obispo de Guadalajara, Ruiz de Cabañas, cuyo coche por orden del jefe insurgente no fue perseguido. A pesar de ello, el episodio le valió al cura de Nopala una excomunión nominal (Bustamante, 1961: 415-418). ${ }^{5}$ Ignacio Rayón comunicaba a Morelos varios de los hechos de armas antes consignados:

La división del brigadier Correa, cura de Nopala, asociada de la del coronel hijo de Villagrán, derrotó enteramente la fuerza que había en la villa de Cadereyta, tomando todas las armas y pertrecho. Las mismas en Calpulapa con notable desigualdad acometieron al convoy que iba de México para tierra adentro, y sin pérdida para nuestra parte, mataron trece dragones y un europeo, haciéndose de las armas y montura y tomándoles a más quince mulas cargadas de pertrecho (Herrejón Peredo, 1987: 181-182).

Como se advierte, había colaboración entre El Chito Villagrán y el cura Correa. Habría también diferencias. No es, pues, tan simple esa relación de altibajos. Algo semejante acontecería respecto a la Suprema Junta Nacional Gubernativa creada por Ignacio Rayón en Zitácuaro el 22 de agosto de ese año. El cura Correa acataba sus disposiciones. Incluso había ido en su auxilio, cuando

5 En "Satisfacción que da el cura Correa a sus coinsurgentes" se da como fecha de la batalla de la Venta La Hermosa el 25 de septiembre (Cadena Guerrero, 1996: 115-116). se dio el ataque de Calleja a Zitácuaro a fines de 1811 y protegió a la Junta en su peregrinación hasta Tlalchapa. Vuelto a Nopala, a principios de febrero de 1812, ahí redactó una proclama para reanimar a sus seguidores, con cuya colaboración plantó fundición de cañones. Con dos de ellos y tropa de 700 hombres participó en la campaña de Rayón sobre el valle de Toluca en abril de 1812 (Bustamante, 1961: 418-419). ${ }^{6}$

\section{Peticiones de Morelos, altibajos en la guerrilla y creación de Departamentos}

Morelos, sitiado en Cuautla, solicitó el apoyo de los Villagranes, que no llegó. Julián se excusó con fútiles razones (García, 1910: 381; Guedea, 1995: 422). Tal vez se debió a que estos guerrilleros estaban empeñados en sus propias campañas. Colaboraron en efecto en la toma de Atotonilco el Grande el 6 de abril de 1812, acción que facilitaría el que otros insurrectos tomaran Pachuca el 23 del mismo. A raíz de la entrada en Atotonilco se dio una correspondencia epistolar entre el párroco Diego Antonio Rodríguez y El Chito Villagrán (Van Young, 2006: 355-358). Una supuesta contestación de éste, fechada en Zimapán el 14 de abril, en que argumenta sobre la justicia de la causa, no puede haber sido redactada por él, sino por algún experto en teología o en cánones, ni siquiera por cualquier cura como Manuel Correa. Pudo ser alguien como el huichapense José Antonio Magos, doctor en cánones. Además, el encabezado de la carta incurre en un error al otorgar el grado de mariscal de campo a José María Villagrán (El Chito) el 14 de abril de 1812, siendo que su nombramiento ocurrió hasta septiembre. Esto sugiere su falta de autenticidad.

Por lo demás, volviendo a la colaboración con Morelos, el propio Ignacio Rayón, no obstante que había enviado auxilios en los inicios del sitio, luego no apoyó a Morelos como éste lo requería, pues su campaña sobre Toluca, simultánea al sitio, distrajo tropas virreinales que no pudieron concurrir a Cuautla. Mas luego del rompimiento de 6 Véase Cadena Guerrero (1996). 
aquel sitio, las tropas virreinales se redistribuyeron y un contingente bajo las órdenes de Pedro Monsalve atacó Huichapan a principios de julio de 1812 con 500 hombres. José María Villagrán lo rechazó exitosamente y por otra parte recibía noticia de que la insurgencia había prendido en el puerto de Tuxpan. ${ }^{7}$

Los realistas habían asentado lo principal de sus tropas en Ixmiquilpan y cerca de Actopan, al mando de Rafael Casasola y Domingo Claverino respectivamente. El primero de ellos, luego de haber destruido un acantonamiento de insurgentes en El Portezuelo, se dirigió a Alfajayucan donde había un tianguis muy concurrido, por ser domingo de Ramos, 21 de marzo de 1812. Casasola entró matando e hiriendo a aquella población civil: dejó al menos 150 muertos y se robó cuanto pudo llevar. El pretexto era que Alfajayucan era un punto en el que solían entrar Villagrán y otros jefes insurgentes. Posteriormente, reunido con Claverino, Casasola desalojó el 10 de mayo a los insurrectos de Pachuca. Del 24 al 30 de mayo se concentraron varios jefes insurgentes, entre ellos El Chito Villagrán, Serrano, Osorno, Cañas, Espinosa y González para tomar Tulancingo, plaza defendida por Piedras. Estuvieron a punto de tomarla, pero la llegada de Claverino los obligó a retirarse. Claverino avanzó luego al estratégico punto de Calpulalpan, donde los rebeldes se habían fortificado; los desalojó de allí y los batió en la venta de Irolo (Alamán, 1968: 102-105).

Estos reveses de la insurgencia de alguna forma parecían compensados con una conquista de Julián Villagrán, quien a mediados de 1812 se apoderó del real de Zimapán, donde fijó su cuartel, dejando a su hijo El Chito el control de Huichapan. En aquel real de minas se fortificó construyendo parapetos con 15 cañones de diverso calibre y una fuerza considerable, aunque mal armada. Al mismo tiempo prosiguió la explota-

7 Julio 12: 'El capitán Pedro Monsalve es rechazado al atacar a Huichapan y perseguido hasta San Juan del Río': "Diario de sucesos políticos y de guerra de la Independencia” (SEP, 1927: 412). Los Villagranes lo participaron verbalmente a Rayón en visita a Tlalpujahua el 7 de agosto (SEP, 1985: 58). ción del mineral acuñando gran cantidad de monedas de plata, algunas de las cuales llevaban la efigie e inscripción del propio Julián Villagrán (Van Young, 2006: 366, 352). Logró también que la Junta formalizara varios nombramientos de la tropa del departamento de Zimapán (Guedea, 1995: 234).

Por esos días, la Suprema Junta Nacional Gubernativa resolvió dividir todo el territorio de la insurgencia en cuatro Departamentos: el Norte, que fue encomendado a José María Liceaga, Vocal de la Junta; el Poniente, a Sixto Berdusco, también Vocal; el Sur, a José María Morelos, recientemente nombrado Vocal; y el Oriente, al Presidente de la Junta, Ignacio Rayón. Los cuatro a partir de entonces se nombraron capitanes generales y tendrían facultades omnímodas en cada territorio, y en particular deberían llevar a cabo visitas que reorganizaran los territorios insurgentes. ${ }^{8}$

El Departamento del Oriente abarcaba la franja oriental de la intendencia de Valladolid de Michoacán, una porción del sureste de la intendencia de Guanajuato, gran parte de la intendencia de México, esto es, los actuales estados de México, Querétaro, Hidalgo y Tlaxcala, así como parte de Morelos; asimismo, la parte septentrional de las intendencias de Puebla y de Veracruz y el área de la actual Ciudad de México. La principal sede de su autoridad fue Tlalpujahua. De esta manera, la región en la que operaban los Villagranes correspondía a este Departamento del Oriente encabezado por Ignacio Rayón.

El Presidente de la Junta esperaba de los Villagranes una franca colaboración, no sin recelo por el antecedente criminal de José María, El Chito, así como por la dudosa justificación de su padre Julián en la muerte

8 El acuerdo de separación de los vocales fue publicado en el llustrador Americano del sábado 20 de junio de 1812, núm. 8, pp. 29-30; facsimilar en García (1910). La reunión en que se distribuyeron territorios se verificó en la hacienda de Tiripitío, cerca de Tuzantla (Bustamante, 1961: 427). Ni él ni otros historiadores dan la fecha precisa de la reunión en Tiripitio. Me parece que debió ocurrir entre el 3 y el 10 de julio, pues Berdusco todavía fecha un comunicado en Sultepec el 30 de junio y él mismo el 15 de julio ya llevaba algunos días internado en el centro de Michoacán. 
que había infligido a Miguel Sánchez (Van Young, 2006: 340-348). Para desvanecer tales prevenciones, El Chito se apersonó en Tlalpujahua el 7 de agosto para manifestar a Rayón sus logros en la insurrección, así como su adhesión y voluntad de acatamiento. En correspondencia, su padre Julián y él recibieron de parte de Rayón los títulos de teniente general y mariscal, respectivamente, "en virtud de los servicios, antigüedad y mérito de estos jefes que con honor han sostenido en el Norte las armas nacionales". Concertaron una visita del presidente a Huichapan, cuya inspección, control y fomento sería uno de los principales retos de Rayón, amén de una campaña con el fin de apoderarse de Ixmiquilpan, punto realista de importancia estratégica (SEP, 1985: 58). ${ }^{9}$ No pocos de los episodios de ese viaje se fueron consignando de manera sucinta en un Diario que llevaba el secretario de Rayón y constituye su fuente principal para la historiografía.

\section{Interpretación reflexiva}

Hasta aquí podemos caracterizar el tipo de guerra de los Villagranes y otros del rumbo. Presentan rasgos del guerrillero partisano: irregularidad, movilidad, apego a la tierra y aspectos de crueldad que los relacionan con la guerra civil, pues los Villagranes la ejercen contra enemigos donde la mayoría no eran peninsulares, incluso contra los renuentes a obedecerlos. Es indispensable señalar que la crueldad y la decisión de aniquilar estuvieron alimentadas una y otra vez por la bárbara represión de José de la Cruz y continuadores, no sólo con los rebeldes, sino también contra familias y población civil. Pero en cuanto al compromiso político, está oscurecido desde el origen de su incorporación al movimiento de Hidalgo por sus antecedentes criminales y su marcada envidia. Les interesa sobre todo defender sus intereses personales y de grupo local prepotente. La meta de la independencia no se

9 José María Villagrán despacha a José Manuel Alcántara a hacerse fuerte en Alfajayuca (Guedea, 1995: 478). excluye, pero ocupa un segundo plano. En este sentido, hay correspondencia con "la otra rebelión" descrita por Van Young. La intención de la guerra de independencia por parte de los Villagranes, si bien subordinada, explica su acercamiento al Presidente de la Junta, y las promesas de acatarla a cambio de otorgamiento de grados, aprobación de movimientos y tolerancia de conductas.

Para este acercamiento intervino el otro guerrillero, Manuel Correa, que coincide con los Villagranes en varios puntos -guerra irregular, movilidad, apego a la tierra-, pero se distancia sobre todo en el compromiso político y en evitar la crueldad. En el compromiso político, Correa acata a la Junta, se coordina efectivamente con ella, colabora en su protección y en ataques. En él es patente la coincidencia con la dirección de la insurgencia. No entra en "La otra rebelión", a pesar de que se le haga aparecer ahí. Sin duda conoce y asume los Elementos de nuestra Constitución de Rayón, pues andaba con él cuando los redactó, y en este sentido busca cambios sustanciales para toda Nueva España por la vía de una revolución, como la conciben Guzmán y Lempérière. Para lograrlo, Correa acepta recibir y dar colaboración a los Villagranes en la guerra irregular, particularmente en asalto a convoyes. Por eso se distingue de la formalidad de Rayón, quien pretendía insertarse en una guerra regular. Por lo demás, la incorporación de Correa en la lucha armada fue muy distinta a la de los Villagranes. En él privó la reacción ante las medidas que la represión había tomado contra él y sobre todo con gente de su parroquia. Toda esta caracterización ofrecerá cambios y profundizaciones en una siguiente fase de la lucha.

\section{Se emprende la visita de Huichapan}

La visita a Huichapan se prolongaría por mes y medio. El itinerario de ida fue el siguiente: el 26 de agosto de 1812 Ignacio Rayón partió de Tlalpujahua a la hacienda de Solís, donde se detuvo hasta el 31 por la mañana, cuando se dirigió a la hacienda de Tepuxtepec; ahí se quedó hasta el 5 de 
septiembre. Durante esa estancia ocurrió el triunfo de su hermano Ramón Rayón en Jerécuaro, auxiliado por el coronel Polo, que mandó el Presidente desde Tepuxtepec. A este lugar fueron enviados parte del botín y 90 prisioneros de aquella acción: ocho de éstos fueron pasados por las armas. También estando ahí se recibió noticia que el guerrillero Alcántara había atacado con éxito la partida enemiga en Jocotitlán y que Manuel Correa, con su tropa unida a la de Huichapan, había atacado en Calpulalpan otro convoy con mediano éxito.

De Tepuxtepec marchó Ignacio Rayón a la hacienda de La Torre, adonde arribó el mismo 5 de septiembre. El 7 partió de este lugar y llegó a Aculco, "donde el honrado vecindario manifestó con demostraciones de alegría muy decididas la singular complacencia" con que recibía al Presidente de la Junta. Al día siguiente se hizo una excursión al cerro de Ñadó, en que Rafael Polo se estaba fortificando y construyendo una maestranza desde febrero de aquel año. De vuelta en Aculco recibió correspondencia del avance de la causa en Orizaba, Zacatlán y Apan. A este rumbo el Presidente Rayón delegó como visitador a Ignacio Martínez, librándole el día 10 un reglamento político, militar y económico. Hasta el 12 salieron para Nopala y de ahí a Huichapan, donde arribaron el 13 de septiembre con un contingente de 457 soldados. Fueron recibidos con extraordinario repique de campanas. Dos cosas llamaron la atención de los visitantes: la adhesión de los habitantes a la causa insurgente y la fortificación de la plaza. En cuanto a lo primero, quedó este testimonio:

tanto la tropa como el vecindario de esta población benemérita, que constante en los principios de patriotismo y honor, han querido más bien ser sacrificados, que doblar cobardemente la cerviz al infame yugo del déspota, han demostrado las virtudes que caracterizan a un pueblo amante hasta el extremo de sus legítimas autoridades (SEP, 1985: 68).
Rayón y su comitiva pudieron apreciar al día siguiente las dimensiones de la fortificación huichapense,

que consiste en diez y seis cortaduras, cuya profundidad es de cinco varas y de otras tantas su latitud; diez y seis trincheras al borde de las cortaduras, y en cada una de ellas una tronera de cañón y varias de fusil, siendo el espesor de sus merlones dos varas poco más; veinte baluartes de adobe repartidos en las azoteas de las entradas del pueblo, su espesor una vara y recíprocamente protegidos, siéndolo también de las trincheras respectivas (SEP, 1985: 68-69).

Se contaba al menos con media docena de cañones, algunos de los cuales había querido El Chito colocarlos en lo alto de la iglesia parroquial, a lo que el cura González se había opuesto con amenaza de excomunión (Van Young, 2006: 352). La tropa existente en el lugar ascendía a 707 hombres, distribuidos de la siguiente manera: 85 artilleros, 122 infantes, 301 de a caballo, 115 fusiles y 84 lanzas (SEP, 1985: 70); ${ }^{10}$ pero seguramente las fuerzas de los Villagranes eran mayores, hallándose a la sazón algunas en Zimapán y otras acechando los caminos. Sin embargo, llama la atención que en estos dos días de la llegada de Rayón en su Diario no se mencione a ninguno de los Villagranes, como si no estuvieran, siendo las autoridades del lugar y habiendo concertado la visita. La ausencia de Julián Villagrán sí tiene alguna justificación, por cuanto él más bien solía encontrarse en Zimapán, según dijimos.

\section{La primera celebración del 16 de septiembre}

Como sea, desde que salió de Tlalpujahua Ignacio Rayón traía el propósito de celebrar la conmemoración del 16 de septiembre, en

10 Un insurgente que deseaba el indulto escribió a Querétaro informando la tropa que había en Huichapan una semana antes de la llegada de Rayón: "trescientos setenta y cuatro hombres, con ciento cuarenta y seis fusiles líquidos, una culebrina y seis cañones"; asimismo, ponderaba la escasez de maíz ahí y en Zimapán (AGN, 1809: vol. 12, fs. 91r-92v). 
cumplimiento del artículo 33 de los Elementos de nuestra Constitución, formulado por el propio Rayón desde abril de ese año de 1812 en Zinacantepec durante la campaña sobre Toluca. A la letra dice:

Los días 16 de septiembre en que se proclama nuestra feliz independencia, el 29 de septiembre y 31 de julio, cumpleaños de nuestros Generalísimos Hidalgo y Allende, y el 12 de diciembre, consagrado a nuestra amabilísima Protectora, Nuestra Señora de Guadalupe, serán solemnizados como los más augustos de nuestra Nación (Lemoine, 1965: 225).

En Tlalpujahua se había realizado una de esas celebraciones, el onomástico de Ignacio Allende. En Huichapan se celebrarían dos: la del Grito y la del onomástico de Hidalgo. Equívocamente se habla de cumpleaños, pues eran onomásticos. El festejo por el inicio de independencia fue reseñado así por un testigo presencial:

Día 16.- Con un descargue de artillería y vuelta general de esquilas comenzó a solemnizarse en la alba de este día el glorioso recuerdo del grito de libertad dado hace dos años en la Congregación de Dolores, por los ilustres héroes y señores serenísimos Hidalgo y Allende, habiéndose anunciado por bando la víspera para que se iluminasen y colgasen todas las calles. Asistió Su Excelencia [Ignacio Rayón] con el lucido acompañamiento de su escolta, oficialidad y tropa a la misa de gracias, en que predicó el señor doctor Brigadier don Francisco Guerrero, y al tiempo de ella hizo salva la artillería y la compañía de granaderos de Huichapan; a las doce, en la serenata, compitiendo entre sí las dos músicas, desempeñaron varias piezas selectas con gusto de Su Excelencia y satisfacción de todo público (SEP, 1985: 69).

Esta sencilla relación tiene un significado de trascendencia: forma parte del inicio del culto a los héroes de la independencia, que comenzaba tempranamente, durante el proceso de la guerra que habían desatado. Pero ya dijimos que la primera celebración conmemorativa no fue la del Grito, sino la del onomástico de Ignacio Allende, el 31 de julio, en Tlalpujahua. Obviamente por su misma naturaleza la celebración del 16 era de mayor rango. Con todo, la de Allende tuvo su propio valor y sirvió de modelo a la del Grito.

Incluso es importante mencionar algunos rasgos de ella, que por no repetirlos el cronista, los dio por supuestos en la celebración del 16. Veamos, pues, cuáles fueron y trasladémoslos a la del 16: desde la víspera, 30 de julio, los balcones y ventanas se adornaron con colgaduras; hubo salva de artillería $y$ "en la noche se iluminaron todas las calles y las dos plazas del real". Se colocó en lugar especial el retrato de Fernando VII, considerado por Rayón como útil "ente de razón" para el éxito de la causa. Esto quiere decir que se aprovechaba la tradición de veneración al monarca, pero dándole el valor más de una figura ideal que de un ser real. Hubo serenata y aclamaciones del numeroso concurso. "En la mañana siguiente se repitieron las salvas de artillería; se vistió de gala toda la oficialidad y tropa"; se formó ésta en el mejor orden; presidiendo Rayón el desfile, se dirigieron a la iglesia parroquial, donde se cantó misa y Te Deum con sermón a cargo del mercedario fray Francisco Guerrero (García, 1910: 57-60)."1"

Por desgracia no ha llegado hasta nosotros la pieza oratoria de aquel primer festejo patrio-religioso, como tampoco el sermón patriótico del 16 de septiembre en Huichapan, debido igualmente a fray Francisco Guerrero.

\section{La proclama del 16 de septiembre de 1812}

A cambio de la publicación del sermón, tenemos el texto de una proclama o manifiesto a los insurgentes suscrito por Ignacio Rayón y su secretario Ignacio Oyarzábal, que llevaba el Diario, datada ese día en el Palacio Nacional. No dice Huichapan, pero obviamente era el lugar (Hernández y Dávalos, 1877: 418-422). Y no debe sorprendernos que se

11 Ilustrador Americano, Tlalpujahua, 1 de agosto de 1812, núm. 20. 
diga Palacio Nacional, pues dondequiera que Rayón como Presidente de la Junta ejercía funciones y firmaba algún documento oficial -así fuera, por ejemplo una casa pueblerina de Tlalchapa-, el sitio se convertía en Palacio Nacional. No sabemos dónde se hospedó Rayón durante el mes y medio que vivió en Huichapan. Una constante tradición oral señala el lugar desde el cual el Presidente de la Junta también presidió la celebración del 16 de septiembre: el edificio conocido como el Chapitel (Guerrero Magos y Guerrero Trejo, 1972: 22). Pudo ser también su morada y pudo también desde ahí hacer una arenga al público con algunas ideas de la proclama.

A pesar de que la proclama o manifiesto expresamente señale como su autor a Rayón, años después, ya consumada la independencia y muerto Rayón, Andrés Quintana Roo afirmó que él "extendió un manifiesto con el título de Aniversario, por encargo de la Junta de Zitácuaro"; que lo hizo, aprovechando medio día en que Rayón, yendo de camino a Huichapan, se detuvo a visitar el fuerte de Ñadó; que tal documento de aniversario debía publicarse tres días después, y que lo concluyó festinadamente, porque se dio la voz de "Tenemos al enemigo encima".12 Como se advierte, en primer lugar se afirma la presencia de Quintana Roo en el viaje, cosa que el Diario de Rayón omite, porque de alguna manera lo supone al hablar de que la imprenta se había trasladado de Tlalpujahua a Huichapan y sabemos que se continuaron ahí los periódicos insurgentes de entonces, cuyo principal redactor era Quintana Roo. Por otra parte, el encargo no era precisamente de la Junta, que estaba dispersa, sino de su Presidente Rayón. Me parece que la redacción de la proclama tuvo que hacerse con indicaciones precisas y correcciones de Rayón, que no carecía de conocimientos del fondo y forma retórica del asunto. Como sea, hizo suya la

12 Esta autoría de la proclama fue referida en un agregado a la "Oda a la Patria" del propio Quintana Roo en el Suplemento de El Amigo de la Religión. Puebla, 1839, p. 65 y ss. (González Obregón, 1966: 619-632). Además, el agregado original y otros papeles fueron obsequiados por Quintana Roo a José María Lafragua: Biblioteca Nacional de México, fondo Lafragua, núm. 928 (Rublúo 1967: 4-9). proclama, de suerte que podemos hablar de una autoría compartida. ${ }^{13}$

El cuerpo de la proclama es una remembranza de los principales avatares, triunfos y derrotas por los que había pasado la causa de la insurgencia durante los dos años transcurridos. Es el primer recuento de la gesta insurgente. Dolores, Guanajuato, Las Cruces, Aculco, Guadalajara, Puente de Calderón, Zacatecas, el Piñón, Zitácuaro, Toluca, Tenango, Cuautla, Lerma, Sultepec, etcétera, así como algunos de sus generales; se alude a Rayón, pero no se menciona su nombre; en cambio, se tributan elogios a Morelos expresamente, incluso a los Villagrán, anfitriones a la sazón del Presidente de la Junta. Dice a este propósito la proclama:

Por todas partes se dejan ver los trofeos del vencimiento, en tanto que el esforzado Villagrán, posesionado del Norte, acomete sin interrupción las reuniones de esclavos que infestan su demarcación, intercepta convoyes, obstruye la comunicación al enemigo y lo hostiliza constantemente con la lentitud más funesta (Hernández, 1877: 420)

En la proclama, y en la realidad, el panorama final, en septiembre de 1812 ofrecía esperanzas de triunfo, pues como vimos la Junta había rediseñado el proyecto de insurgencia dividiendo el territorio en cuatro Departamentos. La medida estaba dando resultados y el gobierno virreinal ya no se daba abasto parar resistir tanto frente organizado. Llama mucho la atención que en toda la proclama no se mencione para nada al rey; en cambio, sí se habla de independencia, que en el contexto es absoluta. De tal manera que en esta ocasión el Presidente de la Junta quita la máscara del fernandismo, frecuente en él. El final de la proclama es una exhortación elocuente:

13 Extrañamente y sin fundamento alguno, Alamán (1968: 133) dice que ese manifiesto, es decir, la proclama, fue remitido a Rayón desde México. Las fuentes dicen otra cosa. Tampoco hay fundamento para decir que se imprimió hasta la vuelta de la imprenta a Tlalpujahua. Para eso y la continuación de los periódicos se había hecho el traslado de ella y del autor editor Quintana Roo. 
Redoblad vuestros esfuerzos, invictos atletas que combatís la tiranía, salvad vuestro suelo de las calamidades que la amenazan, sed la columna sobre la que descanse el santuario de su independencia; animaos a la vista de los progresos hechos en sólo los dos años sin tener armas, dinero, repuestos, ni uno siquiera de los medios que el fiero gobierno prodiga para destruirnos. La nación, llena de majestad y grandeza, camina por el sendero de la gloria a la inmortalidad del vencimiento (SEP, 1985).

No hay elementos para suponer que esta proclama fue pronunciada de viva voz. Corrió impresa y llegó a los otros Departamentos de la insurrección. Incluso un ejemplar fue enviado seguramente por uno de los Guadalupes a Londres donde lo reprodujo fray Servando Teresa de Mier en su Historia (Guerra, 1813: 749-759). ${ }^{14}$

\section{La celebración del 29 de septiembre y su sermón}

También se hizo fiesta el 29 de septiembre, onomástico de Hidalgo. Era otro intento de educar en forma práctica a la población en una nueva identidad para el proyecto de nueva nación que se gestaba. Por ignorancia, los organizadores y la crónica confundieron día de santo con cumpleaños, pues decían celebrar el natalicio, que en realidad había ocurrido el 8 de mayo. Como sea, se repitieron los puntos del programa del 16 de septiembre, mutatis mutandis. Uno de estos cambios fue el orador, pues el predicador de oficio, el mercedario Guerrero, había fallecido la víspera. Dice así el testigo presencial:

Día 29.- En este día se celebraron los años del serenísimo Señor don Miguel Hidalgo y CostiIla, con una solemne misa de gracias, a la que asistió Su Excelencia con su escolta y oficialidad y un inmenso concurso; predicó el Señor Doctor Brigadier don Francisco Lorenzo de Velasco un sermón lleno de unción y de ternura, hizo salvas la artillería de Huichapan y

14 La reprodujo también Bustamante (1961). No conozco un impreso original, pero lo refiere Garritz Ruiz (1990: 329). la infantería de Zitácuaro: en la serenata tocó la música piezas de mucho gusto, y las colgaduras e iluminación de las calles en la noche realzaron el brillo de una función dictada por el reconocimiento y gratitud, y dignísima de su ilustre, inmortal y benemérito objeto (SEP: 1985: 71-72).

Así, pues, el lugar del fraile Guerrero en el púlpito fue ocupado por un fogoso y joven clérigo, que acababa de incorporarse a la insurgencia con escándalo del partido realista, pues además de doctor teólogo, era canónigo e hijo de prominente funcionario realista. Se llamaba Francisco Lorenzo de Velasco y sería personaje de comedia y tragedia (Miquel, 1969: 593-594). A los pocos días la pieza oratoria fue publicada en Tlalpujahua. Es el primer sermón insurgente que, gracias a reedición de Ernesto Lemoine, conocemos en su texto (Velasco, 1812, en Lemoine, 1980: 22-27). El epígrafe inspirador de la prédica es un versículo del Apocalipsis 12:10: "Y escuché una voz que decía en el cielo: Ahora se ha realizado la salvación y la fuerza, puesto que ha sido arrojado el acusador de nuestros hermanos".

El texto se interpretaba como la derrota y expulsión de Satanás por el arcángel san Miguel. No cabe duda que se prestaba a las circunstancias. Mas dejando como en suspenso el interesante paralelismo, el orador pasa a un exordio de corte ciceroniano, con una serie de proposiciones condicionales que terminan por captar la benevolencia de los oyentes, al señalarles, como lugar al que ellos también aspiran, "la cumbre del vencimiento, donde están depositadas la honra, la gloria y la inmortalidad". En la proposición del discurso, que incluye la partición, establece claramente el mencionado paralelismo, columna vertebral del discurso: así como la Iglesia celebra el triunfo de san Miguel, así también la Patria recuerda la empresa gloriosa de otro Miguel. Ambos lucharon contra el espíritu de soberbia arrogante y contra el sórdido interés: el arcángel contra la soberbia luciferina, el mexicano contra la soberbia peninsular. Entonces, ¿cuál deberá ser la memoria que se tribute al primer héroe de la Patria? 
La argumentación, consiguientemente, se desenvuelve en dos partes, la narración y la confirmación, cada una subdividida a su vez en otras dos. Primero, lo relativo a san Miguel: a) La soberbia, "genio primogénito del abismo", penetró en "un espíritu de primer orden" que osó levantarse contra Dios. b) El cielo se estremeció. Un príncipe celestial grita "¿Quién como Dios?” y se traba la lucha. Lucifer se ve expelido.

La segunda parte, la confirmación, relativa a nuestro Miguel, se desarrolla así: a) El espíritu de orgullo se enseñoreó de este suelo con la consiguiente humillación, de manera que "una obediencia sin ejemplo y una fidelidad asombrosa nos hacía besar la mano misma que nos hería". Cuando la perfidia arrancó del trono a Fernando, la América quedó burlada y sujeta a "dura servidumbre [...] tiránica opresión”. b) Pero Dios suscita un genio singular y extraordinario, "un espíritu superior", Hidalgo, quien ha de superar el "muro de bronce" que en razón de sus circunstancias lo apartaba de la guerra. Mas "la voz de la patria oprimida la escuchaba en todos lugares". Y por la "alta opinión" (Velasco, 1812: 24) que tenía, los pueblos lo reconocen y proclaman por su libertador. La imagen de Hidalgo caudillo tiene entonces otro paradigma irresistible para el orador: Moisés al frente del pueblo hebreo. La figura de Israel aplicada a México había sido cara a los criollos, sobre todo a partir de que la aparición de la Virgen de Guadalupe se consideró favor singular: "No hizo cosa igual con otra nación".

El orador Velasco prosigue haciendo ver cómo ante el caudillaje de Hidalgo se levanta la infamia de sus acusadores, mas ellos no son capaces de impedir que a través de triunfos y derrotas la empresa se recupere aun después de su muerte. La refutación y la peroración en verdad desmerecen frente al buen desarrollo anterior. La refutación sólo se refiere a triunfos y reveses por "juicios inescrutables del Altísimo", en tanto que la peroración acaba precipitadamente con una invocación a la Virgen de Guadalupe pidiéndole su protección para el movimiento, como "causa tuya” (Velasco, 1812: 25). Había elementos para una recapitulación vigorosa y una exhortación solemne.

Como sea, el sermón de Velasco es de primordial importancia. Los anteriores sermones del fraile Guerrero se los llevó el viento. El de Velasco pronunciado en Huichapan marca efectivamente la pauta para la oratoria de epopeya nacionalista, ya en el púlpito, ya en la tribuna. El plan en que se pinta primero la situación anterior al Grito, luego la hazaña de Hidalgo y por último sus consecuencias, será el esquema fundamental, trilladísimo desde entonces. El paradigma de san Miguel no será muy socorrido, pero el de Moisés sí reaparecerá con frecuencia. Igualmente el tema de la increíble obediencia será reiterado por no pocos oradores. En cambio, la paradoja de proclamar simultáneamente el rechazo de gachupines y fernandismo sólo durará hasta mediados de 1813. Así pues, el inventor de panteón y culto patriótico no fue Carlos María de Bustamante. Rayón y su gente se le adelantaron y no sólo en la celebración del festejo, sino también en su carácter de principio obligatorio, como se estableció en los Elementos constitucionales (Lemoine, 1965: 173).

\section{Reivindicación de la prensa insurgente en Huichapan}

De las dos piezas que hemos analizado -la proclama del 16 de septiembre y el sermón patriótico de Francisco Lorenzo de Velasco-, la primera se imprimió en Huichapan y la segunda se empezó a imprimir ahí mismo, aun cuando el pie de imprenta final diga Tlalpujahua. Lo anterior es evidente, porque la presentación de la pieza oratoria de Velasco fue hecha por José María Revelo, el impresor de la Imprenta Nacional, quien data su presentación en Huichapan el 12 de octubre (Velasco, 1812: 22), día en que salió la imprenta de este lugar de regreso para Tlalpujahua.

Todavía más: como esa Imprenta Nacional había salido de Tlalpujahua a Huichapan el 28 de agosto y de este lugar salió a Tlalpujahua el 12 de octubre, entonces en Huichapan se debieron publicar varios ejem- 
plares de los periódicos insurgentes, esto es, cuatro números del llustrador Americano: $23,24,25$ y 26 , correspondientes a los sábados 12 y 26 de septiembre; 3 y 10 de octubre de 1812; así como siete números del Semanario Patriótico Americano, dirigido por Andrés Quintana Roo: 7, 8, 9, 10, 11, 12 y 13, correspondientes a los domingos 30 de agosto, 6, 7, 13, 20 y 27 de septiembre, y 4 y 11 de octubre de 1812. Por lo tanto, Huichapan debe ocupar un lugar importante en el periodismo insurgente y se debe considerar que ahí mismo, el domingo 30 de agosto de 1812, fecha del número 7 del Semanario Patriótico Americano, se hizo la primera publicación impresa en territorio de lo que luego sería el estado de Hidalgo.

Los historiadores de la prensa insurgente en México no lo han advertido, porque el primero de ellos, Genaro García, cometió un error que otros han seguido, como José María Miquel i Vergés y Tarsicio García (García, 1910: 21; Miquel, 1941: 83, 113, 119; García Díaz, 1971: 577-592). El error no sólo afecta el hecho de la imprenta en Huichapan, sino que disminuye el tiempo de la imprenta en Tlalpujahua, tiempo que García y seguidores otorgan a Sultepec, donde se había iniciado la publicación del Ilustrador Americano y donde suponen equivocadamente que también comenzó el Semanario Patriótico Americano. El error original de Genaro García se debe a que únicamente leyó la parte del Diario de Rayón donde se dice que la imprenta salió para Tlalpujahua el 12 de octubre de 1812, suponiendo que hasta entonces había salido de Sultepec; pero no leyó que páginas atrás el mismo Diario asegura que la imprenta había salido de Tlalpujahua para Huichapan. Con ese error Genaro García cometió otro, al decir que la imprenta había estado en Sultepec hasta ese 12 de octubre y consiguientemente incide en cascada de equivocaciones, como expresar que el /lustrador Americano y el Semanario Patriótico Americano se estuvieron publicando en Sultepec hasta esa fecha, con lo cual también disminuyó notablemente el tiempo de esas publicaciones en Tlalpujahua.
Además, la opinión de Genaro García y seguidores resulta incompatible con otros hechos históricos. Sultepec había caído en poder del gobierno virreinal desde fines de junio de 1812, de manera que la Suprema Junta de la insurrección hubo de salir de ahí por esas fechas y consiguientemente no hubo ya periodismo insurgente en Sultepec. Más todavía. El mismo llustrador Americano, que supuestamente habían leído Genaro García y seguidores, en su número 7 del 17 de junio de 1812, página 27, dice:

Sultepec 16 de junio. [...] la Suprema Junta [...] providenció la salida de nuestra tropa, erario, imprenta, etc., para no dejar a los contrarios más que el recinto vacío, ni aventurar una acción cuyo éxito seguramente hubiera sido muy favorable a sus miras, atendida la inferioridad de fuerzas con que nos hallábamos. ${ }^{15}$

De tal suerte que la imprenta insurgente salió de Sultepec entre el 14 y el 16 de junio de 1812. Ignacio Rayón llegó a Tlalpujahua a mediados de ese mes y lo más probable es que la imprenta haya arribado junto con él, o bien poco antes o poco después. Así las cosas, el Ilustrador Americano siguió publicándose en aquel real de minas y ahí comenzó el Semanario Patriótico Americano, excepto el intervalo considerable en que se editaron en Huichapan juntamente con otros documentos importantes, como la proclama del 16 de septiembre.

\section{Medidas de Rayón y el ataque a Ixmiquilpan: otro tipo de guerra}

En los siguientes días a las celebraciones del 16 y 29 de septiembre, Ignacio Rayón tomó diversas medidas sobre fincas de la nación (SEP, 1985: 70; Guedea, 1995: 287). El 17 y 19 de septiembre se pasó revista a las tropas

15 Es probable que el número 8 del 20 de junio se haya impreso de camino en Ixtapan de la Sal u otro punto. Por otra parte, hay que advertir que los 11 números que van del 9 al 19 no figuran entre los reimpresos que se conocen y que en el número 21 del 5 de agosto, página 64, se dice: "Advertencia. Nuestro //ustrador ha interrumpídose por la necesidad de no fijar nuestra residencia". Se refiere a que no salía a tiempo en los días fijados; pero plantea el problema de su ubicación. 
tanto de Huichapan como a las que conducía Rayón. Es de notar que en las primeras hay una división comandada por otro Villagrán, el coronel José Antonio. Y hubo más de la misma familia enrolados en la insurgencia: Juan José Villagrán, capitán de infantería, y dos homónimos de El Chito: José María Villagrán, teniente coronel, y José María Villagrán, cadete (Guedea, 1995: 285, 239, 240).

El 22 del mismo el Presidente disponía que El Chito Villagrán asaltara dos convoyes y atacara Tula (SEP, 1985: 70). Antes de que salieran, el abogado general quería llevar cuenta de todo, en atención quizá a la informalidad de los Villagranes; y así se hubo de registrar la plana mayor de El Chito (Guedea, 1995: 286). Parece que el primer convoy, salido de México, no pudo ser atacado, pero el segundo, que iba de Tierra Adentro hacia México, sí fue asaltado por El Chito, obteniendo 2700 cabezas de ganado menor. Tampoco se llevó a cabo el asalto a Tula, por ser superior la guarnición; en cambio, atacó Chilcuautla el 29 de septiembre con pérdida considerable del enemigo, pero no logró tomarla por falta de artillería. Tal vez no alcanzó a recibir dos cañones, uno con calibre 12 y otro de cuatro, que había enviado su padre Julián desde Zimapán. En el ataque murió un primo y homónimo de $E /$ Chito, el ya mencionado coronel José María Villagrán, a quien se le hizo solemne funeral en Huichapan el 1 de octubre con acuerdo de Rayón (SEP, 1985: 68-72; Van Young, 2006: 352). Se trataba del mismo que en 1809 había protagonizado escándalo y alboroto en el pueblo por sus aventuras adulterinas y mofas al subdelegado, según vimos.

Otras partidas insurgentes que se habían mantenido por Ixmiquilpan (Ortiz Escamilla, 1997: 219) fueron batidas una y otra vez cerca de Atotonilco el Grande entre el 18 y el 22 del mismo mes (SEP, 1927: 413-414). El 7 de octubre llegaba correspondencia de Ignacio Martínez, el visitador de los Llanos de Apan, que dio cuenta de los avances en el cumplimiento de su misión (SEP, 1985: 73). Alrededor del 20 de septiembre, al pasar cerca de Tepeji, él y siete acompañantes, ninguno con fusil, habían sido atacados por una partida realista de 50 hombres al mando de Moreno, pero lograron escapar. En el parte que rindió Moreno y publicó la Gaceta virreinal se dijo que los insurgentes eran más de 170 y los realistas $24 .^{16}$

Uno de los objetivos de la visita de Rayón a Huichapan era combinar con los Villagranes una campaña para tomar Ixmiquilpan, cuyo comandante era Rafael Casasola. El Chito deseaba hacerlo, mas al parecer Rayón lo contuvo con la idea de combinar un ataque mejor planeado bajo su dirección. De esta manera, Rayón concertó la participación de El Chito para el día del ataque. Sin embargo, ya para entonces se había producido tensión entre él y el presidente Rayón, porque éste le reprochaba que viviera en amasiato (Van Young, 2006: 353). Salió la tropa de Rayón de Huichapan el 15 de octubre a la hacienda del Astillero, de ahí ya con Manuel Correa y Manuel Polo, a la hacienda de la Tenería y a Alfajayuca donde arribaron el 17 a mediodía, para salir por la tarde a las inmediaciones de Ixmiquilpan, a fin de reconocer los puntos de la plaza por atacar.

El 18 hacia las nueve de la mañana se avistaron desde Ixmiquilpan hacia el Poniente los primeros dragones insurgentes. El comandante Casasola con 50 de los suyos salió a batirlos, pero no hubo encuentro, pues los insurgentes se replegaron al cerro de la Media Luna, donde terminó de colocarse el campamento de Rayón a las tres de la tarde. A la hora salió de Ixmiquilpan una partida de 60 dragones y alrededor de 40 infantes, ocultándose con arbustos en el paraje del puente sobre el río Tula, inmediato a la población; avanzaron hasta acercarse al punto en que se hallaba descansando la tropa de Manuel Correa. A pesar de esto, los insurgentes reaccionaron con viveza. El coronel Lobato, a cargo de la infantería, protegió el movimiento de los dragones insurgentes, animados por el cuartel maestre Hernández y el coronel Chavero. Tres veces intentó Casasola subir el cerro y las tres fue repelido, dejando muertos a 15 de sus realistas en el campo y siendo otros tantos los moribun-

16 Ilustrador Americano, 10 de octubre de 1812, núm. 26: 81, en Hernández y Dávalos (1877). 
dos en los fosos. Entre los difuntos se hallaron el capitán Mariano Negrete y el alférez de fragata Federico de Álava. En su informe, Casasola trataría de exculpar su temeridad diciendo que los insurgentes tenían dos cañones ocultos y por eso fue rechazado. Al ponerse el sol hicieron otra salida los realistas, protegidos ahora por el mucho fuego de dos cañones del pueblo contra los rebeldes, pero de nueva cuenta fueron rechazados con igual bizarría, aunque por su violenta retirada sólo tres quedaron en el campo. Por la noche desde el campo insurgente se hizo fuego a una vigilancia enemiga, sin que ocurriese más novedad.

El mismo informe de Casasola inserta el texto de una intimación que supuestamente hizo Rayón, luego de haber repelido a los realistas. En ese texto apremia a los defensores y habitantes a rendirse en el perentorio plazo de dos horas con la amenaza de pasar a cuchillo a todos. El mismo informe inserta la respuesta de Casasola, datada a las siete y media de la noche. Es posible la intimación de Rayón. Pero la amenaza de muerte indiscriminada disiente de su carácter, conducta más propia de Casasola, como lo había acreditado en Alfajayucan. Y es poco creíble que la intimación con plazo de dos horas se haya formulado al ponerse el sol. Ciertamente Casasola estaba impresionado y veía, a pesar de la oscuridad, que los cerros circundantes eran ocupados por mucha indiada de Zimapán y del Santuario. En consecuencia, mandó avisos en demanda de auxilio a Tlahuelilpan, Actopan y Chilcuautla. Sólo de este último punto llegaron a deshora de la noche 30 hombres al mando de José Félix Merino.

A las cinco de la mañana del 19 de octubre "se tiró a la plaza el primer cañonazo, y a las siete comenzó a avanzar a ella toda la infantería, la mayor parte de la caballería y dos cañones, quedando con el resto una batería en la eminencia (la Media Luna), para proteger desde ella el fuego de fusil (SEP, 1985)". Manuel Correa y Lobato con sus respectivas tropas llevaron la mayor parte de la ejecución del ataque: penetraron por el puente, echaron abajo dos parapetos y mar- charon hasta la plaza, quedando sólo el último, ya inmediato a la iglesia y convento de San Miguel, en que se habían refugiado los defensores.

Hacia el sureste de Ixmiquilpan se había situado desde la víspera el coronel Casimiro Gómez con sus indios de El Cardonal, y otros de Zimapán y Tecosautla. Ignacio Rayón había ordenado que los acompañara como supervisor de su parte el joven canónigo Francisco Lorenzo de Velasco, el mismo que había pronunciado el sermón del 29 de septiembre. No tuvo necesidad de hacer mayor cosa que admirar el orden y denuedo de aquellos indios, que habiendo acampado en el cerro del Calvario, de ahí avanzaron desde temprano hasta entrar en la población, que al parecer por ese punto no ofrecía la misma resistencia que por el Poniente, pues dispersaron con facilidad al enemigo, penetraron en varias casas y a las dos de la tarde lograban colocar dos cañones sobre la iglesia de El Carmen, que protegieron el avance de la infantería.

Correa, pues, se hallaba a punto de lograr la victoria, para lo cual requería un cañón de mayor calibre -que lo tenía-, pero faltaban balas, que debía aprestar El Chito, quien se hallaba en la retaguardia con los hermanos Polos. Quizá premeditadamente, para impedir que otro se alzara con la victoria, o bien en estado de ebriedad, El Chito nunca se comprometió en la batalla ni aportó las balas de cañón, a pesar de las órdenes del Presidente. Correa, sin dejar de combatir, a las tres de la tarde mandó un parte de la batalla a Rayón, que se encontraba cerca. Le ponderó que el pertrecho se terminaba, que la invencible división de Lobato estaba fatigadísima, que los auxilios esperados -de El Chito- se hallaban a mucha distancia, que podría ser envuelto por la muy probable llegada de refuerzos realistas, y que por tanto iba a ordenar la retirada a la división de El Cardonal. Sin embargo, parece que Correa ignoraba el importante avance de Casimiro Gómez porque éste, o mejor dicho, Francisco Lorenzo de Velasco, no se lo habían comunicado. Aún aguardaron otra hora a $E$ l Chito. Fueron 11 horas de combate. Correa 
ordenó tocar retirada. A pesar de la fatiga, algunos murmuraron, pues ya tenían la victoria en la mano. Casasola no lo podía creer. Le habían matado más de 100 hombres de su guarnición. De los insurgentes sólo hubo cinco bajas y siete heridos. Hasta el día siguiente le llegarían más refuerzos, algunos de los cuales, procedentes de Tlahuelilpan, habían sufrido destrozo por parte de Casimiro Gómez.

El informe de Casasola no deja de contener contradicciones y presenta la sustancia de los hechos de manera muy diversa. Había dicho de la tropa insurgente que eran bandidos e indiada, pero luego precisa que "por el puente y el río pasó toda la gente uniformada de Rayón, infantería y caballería”. Que estos rebeldes colocaron un cañón de a seis a la entrada del pueblo; que los parapetos del primer punto, defendido por José Félix Merino, fueron atacados tres veces, pero reparados; que Merino dejó el puesto por ser golpeado fuertemente, "contuso", y lo sustituyó José García Marín, quien corrió la misma suerte; que el segundo parapeto estaba sostenido por Antonio Fernández con dragones de Santander; y que los atacantes "jamás pudieron vencer esta interesante entrada”. No habla del tercer parapeto. Que en cuanto a la línea del sureste, el barrio del Carmen, los jefes realistas Argumosa, Blanco y Serna "sufrían los tiros de cañón y fusil que los enemigos hacían desde los cerritos, ocultándose por todas partes en lo espeso de la arboleda que rodea este pueblo"; que en esa misma línea comenzó el incendio de casas, pero fue sofocado, porque entonces la tropa de Correa, "que no había adelantado ni una pulgada de terreno", se retiraba con el mayor orden al cerro de la Media Luna.

Según las cuentas de Casasola, tomadas supuestamente de desertores insurgentes, su caballería pasaba de 800 , parte de ellos de los pintos de Tierra Caliente; los fusileros eran 600, de Huichapan y Zimapán, uniformados y disciplinados, "y una multitud de indiada que no bajaba de siete mil hombres". Su artillería consistía en 11 cañones, entre ellos uno de grueso calibre. De los insurgen- tes muertos no da número, pero reitera que fueron muchos, y que llevaban 150 heridos. En cuanto a los realistas muertos en la acción, los reduce a 19, y declara 21 heridos y 23 contusos. Recordemos que de acuerdo con los insurgentes, los realistas muertos fueron más de 100, y que de los suyos sólo hubo cinco bajas y siete heridos.

Rayón y su ejército se dirigieron a Alfajayuca, a donde llegaron el mismo 19. Al día siguiente partieron a la Tenería, y el 21 por la tarde a la venta La Hermosa. De aquí retrocedió el Presidente rápidamente a Huichapan, dejando su tropa para que luego se le reuniera. Arribó hacia el mediodía del 22 en busca de El Chito para reconvenirle por contraventor de sus órdenes superiores. En lugar de acatamiento, aprovechando que Rayón se hallaba casi solo, El Chito no sólo opuso resistencia, sino que de inmediato propaló entre su gente calumnias contra Rayón y dictó una serie de medidas para impedirle que huyera. El Presidente no se intimidó, también dictó sus providencias, pues no todos estaban dispuestos a obedecer a El Chito. Pronto se quedó éste con unos pocos y Rayón controlaba la situación, tanto más que llegó su tropa, ante lo cual El Chito huyó sólo con 20 partidarios. ${ }^{17}$

\section{Altibajos en la subordinación a la Junta}

En un principio, el padre de El Chito, Julián Villagrán, también lo reconvino, pero finalmente condescendió y se declararon los dos en contra de Rayón. Incluso se atrevieron a apresar a Ignacio Martínez, comisionado de Rayón para visitar los Llanos de Apan, en que operaba Francisco Osorno. A su retorno pasó por Huichapan y ahí le echaron mano, pero Martínez lograría escapar aprovechando una borrachera de los Villagranes (SEP, 1985: 89).

\footnotetext{
17 Toda la narración de la batalla y su corolario es una síntesis de estas fuentes: SEP, 1985: 74-76; Partes militares de José Manuel Correa y de Francisco Lorenzo de Velasco, en Ilustrador Americano, 24 de octubre de 1812, núm. 28, pp. 88-92; Parte militar de Rafael Casasola en Gaceta del Gobierno de México del martes 27 de octubre de 1812, III, núm. 307, pp.1127; Bustamante, 1961: 420 (testimonio de Correa); pp. 510-511 (Gaceta y otras fuentes); Alamán, 1968: 219-221 (Gaceta, Diario y Bustamante).
} 
Como sea, la ausencia de Ignacio Rayón se había prolongado y hubo de volver a Tlalpujahua. En realidad este regreso ya estaba planeado desde antes del ataque a Ixmiquilpan, puesto que el 12 de octubre Rayón había dispuesto que la imprenta saliera ese día para Tlalpujahua. Rayón y su escolta marcharon de Huichapan hasta el 31 de octubre y rindieron jornada en la hacienda de Cuachití. El 1 de noviembre llegaron a Aculco donde descansaron el 2; ahí, el Presidente volvió a entrevistarse con el comandante del fuerte de Ñadó, José Rafael Polo, quien presentó a Rayón el inventario de armamento, los gastos del fuerte y la lista de sus oficiales (Guedea, 1995: 287). Al día siguiente, acompañado de aquel comandante subieron otra vez al fuerte; ahí se despidieron y Rayón prosiguió a la hacienda de Solís. El 4 volvieron a descansar y finalmente arribaron a Tlalpujahua el 5 de noviembre (SEP, 1985: 78-79).

Los Villagranes no duraron en su rebeldía, porque el Presidente Rayón comunicaba todo a los otros capitanes generales, solicitando su apoyo, cosa que hicieron. Consta de Sixto Berdusco y de Morelos. El primero lamentó las incomodidades que los Villagranes provocaban al Presidente y luego le aseguró contribuir para tomar venganza de ellos (Guedea, 1995: 207, 151)..$^{18}$ Éstos invocaron a Morelos como única autoridad que reconocían. Pero el caudillo del Sur apoyó a Rayón como a Presidente de la Junta: "Villagrán sólo quiso reconocer a mí y no a la Junta, y que contara con 60,000 hombres; ahora supe que a su hijo le forman causa" (Guedea, 1995: 87). ${ }^{19}$ "Nunca me he prometido buenos resultados de los Villagranes y sus aliados: ya les ajustaremos la cuenta" (Lemoine, 1965: 229).

Entonces Julián aprovechó una comunicación del doctor Magos a Morelos, para reiterar el ofrecimiento de sus servicios (Guedea, 1995: 463). Pero el caudillo del Sur fue claro: "El brindis que me hizo Villagrán no tendrá efecto; éste y Osorno están de

18 Berdusco a Rayón, 22 de noviembre de 1812; Pátzcuaro, 23 de diciembre de 1812.

19 Morelos a Rayón, Tehuacán, 7 de noviembre de 1812. acuerdo en no obedecerme; pero nos son útiles; el cura don Joaquín Gutiérrez vino huyendo de Villagrán" (Guedea, 1995: 88). A los 15 días el propio Morelos comunicaba a Rayón su disposición de castigar a los Villagranes, mas no lo podía hacer por la distancia (Guedea, 1995: 209).

Asimismo, el importante mencionado guerrillero Francisco Osorno, que controlaba la vecina región de los Llanos de Apan hasta Zacatlán, habiendo recibido indicación de la Junta a través de una segunda visita de Ignacio Martínez, desaprobó la conducta de los Villagranes y apoyó a Rayón; incluso fue nombrado comandante de las fuerzas de los Villagranes y se puso en comunicación con Julián para que liberara a Martínez (Herrejón Peredo, 1987: 260; Guedea, 1995: 128, 153; SEP, 1985: 89; Alamán, 1968: 222). ${ }^{20}$ Ni qué decir de Manuel Correa, que no obstante su amistad con los Villagranes, se pronunció contra su sedición, dando informes a Rayón y solicitando se le diese grado de brigadier y se renovara su nombramiento como comandante de Huichapan (Guedea, 1995: 334-335).21

Cuando ya meditaban sobre las desventajas de quedarse solos en su rebeldía, llegó a toda la insurgencia la plausible noticia del triunfo político de los criollos en la Ciudad de México, en que habían ganado los puestos de los 12 electores que habrían de escoger a los miembros del ayuntamiento.

Uno de ellos era Juan de Dios Martínez, elector por Santa Catalina Mártir, tío de José María Villagrán, no sabemos en qué grado. Supuestamente le escribió al sobrino dándole la noticia y ofreciéndole apoyo para la causa. O no fue verdad el envío de la carta y El Chito la inventó, o no la entendió, pues difundió la noticia de que en México ya no gobernaba el virrey, sino el grupo de los 12 electores (Guedea, 1995: 219, 478). ${ }^{22}$ Cierta-

20 Dice que Martínez había sido peor tratado por Osorno. No parece, en vista de los documentos citados. 21 Manuel Correa al secretario Ignacio Oyarzábal, Nopala, 12 de noviembre de 1812.

22 José María Villagrán al capitán Pascual Escarpio de la división de El Cardonal, Huichapan, 5 de diciembre de 1812. Es probable que otro vecino de la Ciudad de México fuera pariente de los Villagranes de Huichapan, un panadero de apellido Villagrán ligado a la so- 
mente dicho elector Martínez fue reducido a prisión por sospechas de tener comunicación con los Villagranes; mas no duraría, pues Calleja mandó liberarlo (Guedea, 1992: 147, 153, 154, 158, 161, 181, 197).

Lo cierto es que los sediciosos tomaron la resolución de subordinarse, y para lograr la venia se valieron de intercesores. El 30 de diciembre llegaban a Tlalpujahua dos clérigos procedentes de Huichapan: el bachiller Mariano Lezama, y el otro, cura interino de Zimapán. Portaban una representación de José María Villagrán, al parecer escrita, en que se arrepentía de su conducta e impetraba la clemencia del Presidente Rayón. Los emisarios acompañaron la representación con súplicas, razones y disculpas y se quedaron en Tlalpujahua hasta el 3 de enero, día en que Rayón los despidió dándoles para ambos Villagranes "el despacho más favorable que podían recibir, atendida la enormidad de sus delitos, y es que la conducta sucesiva de ellos será el garante de un perdón absoluto, o de un severo castigo" (SEP, 1985: 91).

Rayón comprobó que su indulgencia se apoyaría también en la intercesión del fidelísimo Manuel Correa, que estando en Huichapan escuchó a los Villagranes reconociendo sus extravíos y pidiéndole intercediera también ante Rayón. No sabemos por qué echaban la culpa al doctor Magos. Así las cosas volvieron a integrarse a la obediencia del Presidente de la Junta, y al parecer la designación de Osorno como comandante de las fuerzas de los Villagranes quedó sin efecto. Uno de los apoyos más firmes de éstos, Casimiro Gómez, también protestó obediencia a la Junta, bien que seguiría colaborando con ellos, ya subordinados. Por otra parte, cuando Ramón Rayón, hermano de Ignacio, enlistó a los oficiales del cantón de Tlalpujahua el 1 de febrero de 1813, incluyó al mariscal José María Villagrán, El Chito; y por otra parte aparece también un Antonio Villagrán como brigadier (Guedea, 1995: 154-155, 190, 288).

Así pues, todo el episodio de la rebeldía de los Villagranes respecto a Ignacio Rayón

ciedad secreta de los Guadalupes. como Presidente de la Junta, así como su subordinación, muestra que contra lo que dicen Alamán y seguidores (Alamán, 1968: 245), la autoridad de la Junta y en especial de su Presidente no era una mera sombra, sino que realmente era reconocida por la gran mayoría de los insurgentes y operaba hasta doblegar a insubordinados.

Otra cosa sería cuando la propia Junta se resquebrajó internamente por la disensión original de Berdusco, secundado por Liceaga, frente a Rayón. De tal suerte se suscitó grave pugna entre ellos, en la cual los Villagranes se pusieron de parte de Berdusco y Liceaga, y así su subordinación al Presidente sólo duró hasta abril de 1813. Previamente, El Chito hizo creer a Manuel Correa que seguían acatando a Rayón; mas al parecer sólo fue con objeto de que Correa se retirara de Huichapan a Villa del Carbón y procurar luego su desarme, por indicación de Berdusco y Liceaga, cosa que evadió Correa con astucia (SEP, 1985: 104; Guedea, 1995: 112, 393; Bustamante, 1961: 420). Sin embargo, el propio Correa internamente ponderaba que Rayón había cometido imprudencias en su visita al rumbo de Huichapan (Cadena Guerrero, 1996: 118). Como sea, consecuencia de aquella discordia fue el avance realista, la ruina de los Villagranes y la caída de Tlalpujahua el 12 de mayo de 1813 (Alamán, 1968: 286).

En efecto, a pesar de que El Chito todavía pudo atacar con gran éxito un convoy realista, esto aceleró la represalia, pues pronto un ejército de 3000 hombres a las órdenes de Pedro Monsalve emprendió ataque contra Huichapan el 3 de mayo, que cayó en su poder tras encarnizado combate; fue saqueada y muchos defensores y habitantes pasados por las armas. El Chito huyó, pero fue alcanzado y fusilado el 14 de ese mes. Su padre Julián continuó rebelde en Zimapán, pero ante la llegada realista el 30 de mayo, se dio a la huida y hubo de esconderse; uno de sus propios hombres lo traicionó revelando su paradero. Fue ejecutado el 21 de junio del mismo año en la hacienda de Gilitla (Bustamante, 1961: 596-598; Alamán, 1968: 290-294; Van Young, 2006: 354, 366). 
A raíz de estos acontecimientos, la viuda de Julián, María Anastasia Mejía, fue capturada con sus hijas, nueras y criadas. Iban a ser conducidas a la Ciudad de México, pero suplicó la pusiesen en libertad, pues aseguraba que había tratado de que su esposo se retrajera de la insurgencia, y ponía por testigos a sacerdotes de Huichapan, Tecosautla y Zimapán. Por instrucciones del virrey fueron liberadas en octubre de 1813 (García, 1910: 455).

A pesar de ello, la región de Huichapan continuó con presencia de insurrectos. Incluso, otro miembro de la familia, Rafael Villagrán, hermano de Julián, otrora capitán de milicias realistas, y que había ayudado ocultamente a los rebeldes, se declaró insurgente y persistió hasta su rendición e indulto en 1816 (Van Young, 2006: 349). Por otra parte, el huichapense sacerdote José Antonio Magos, de origen otomí, continuaría en la insurrección dominando la Sierra Gorda hasta la consumación de la independencia.

Tal persistencia y extensión de la causa insurgente en diversos niveles de la población de la región de Huichapan no se explican adecuadamente por la personalidad y los intereses particulares de los Villagranes y otros, que aprovecharon un estado de fermentación. Falta un estudio sobre las bases sociales que nutrieron la insurgencia en ese rumbo y junto con ello, indagar en el condicionamiento geográfico.

Como hipótesis podemos plantear que la ubicación estratégica de Huichapan y Nopala, entre México y Querétaro, permitió el asalto constante a convoyes, sobre todo en Calpulalpan, donde se bifurcaban importantes vías de comunicación. Al mismo tiempo, Huichapan y El Cardonal funcionaban como antemurales de Zimapán, que a su vez pareciera principal fuente de recursos constantes de todo orden, no porque todos se produjeran ahí, sino porque era centro de acopio y distribución. Lo remontado de aquel real de minas permitió que Julián Villagrán ejerciera allá un dominio despótico.

Por otra parte, Ixmiquilpan, en poder de los realistas, era amenaza constante, impi- diendo la conexión franca entre Huichapan y El Cardonal, así como con otros grupos insurgentes que se extendían de Tulancingo hasta los Ilanos de Apan. El conjunto de estos grupos, incluidos los de Rayón por el occidente y suroeste, así como los de Liceaga y Berdusco, formaban parte de una media luna que podía irse acercando a la capital del virreinato y cerrarse con la otra media luna que por las mismas fechas, segunda mitad de 1812 y principios de 1813, ocupaban fuerzas de Morelos por el sur y el oriente del centro del país.

\section{Conclusiones}

El carácter de guerrillero partisano aplicado a los Villagranes insurgentes permanece en cuanto a la irregularidad de su lucha, la movilidad, los cambios bruscos, el apego a la tierra y el sello de guerra civil, según se puede apreciar por la preferencia de ataque a convoyes, a menudo exitoso. Pero no sólo continúa la falta de compromiso político, en el sentido de no ir más allá de sus intereses de grupo local, sino que se profundiza, pues la coordinación con Rayón funcionó poco, entró en crisis por despecho en precedencias que Rayón asignaba a otros y aun por detalles muy personales, como la desaprobación del amasiato de El Chito, y en el momento decisivo del ataque a Ixmiquilpan, por envidia del triunfo ajeno. Incluso el apego a la tierra, entendido como conocimiento y afecto no sólo al terruño, sino a su gente, se desvanece en el episodio de la llegada de Rayón casi solo a Huichapan, luego de la retirada de Ixmiquilpan: El Chito pretende que su gente lo aprehenda, pero en vez de ello se vuelven contra él y lo hacen huir. Lo anterior insinúa que el liderazgo de los Villagranes era a la fuerza. A pesar de importantes contribuciones en la lucha, ni la revolución ni la independencia eran la prioridad para los Villagranes. Esto se confirma por los sucesos posteriores: la subordinación a Rayón, luego que los vocales de la Junta, incluido Morelos y otros guerrilleros desaprobaron su conducta apoyando al Presidente, fue pasajera. 
En cuanto a Manuel Correa, mantiene rasgos de partisano, con fuerte compromiso político, integrado a una revolución por la independencia, con la invocación provisional y estratégica a Fernando VII, como quería Rayón. El contingente que llevó el Presidente a Huichapan habla que su guerra no era al estilo partisano. $Y$ aunque trataba de dar y recibir apoyo de guerrilleros, buscaba principalmente hacer guerra formal con cánones de reglamento, tropa uniformada y disciplinada, sujeta a un sistema de rangos militares; cúpula insurgente definida en cuatro departamentos; todo en el marco de los Elementos de nuestra constitución. Su excesivo formalismo y la ambición de mantener la suprema autoridad no raras veces lo volvía intransigente y le enajenaba voluntades. Su lucha no escapaba a notas de una guerra civil, pero evitaba la crueldad. Y desde luego se trataba de una revolución de independencia, bien que gradual y nominalmente fidelista.

En cuanto a la primera conmemoración del Grito en Huichapan, programada desde los Elementos de nuestra Constitución, se tomó el modelo de la que hubo en Tlalpujahua para el onomástico de Allende. En el campo de las representaciones y de los símbolos significa que Rayón estaba dando al movimiento una identidad y una raíz histórica propias, diversas de las expresadas en la jura del rey y otras celebraciones de la monarquía, bien que se hayan tomado algunos de sus elementos. Tal significado peculiar de la conmemoración en Huichapan se implica en la proclama de Rayón del 16 de septiembre, en cuya redacción participó Andrés Quintana Roo.

De ella se desprende que la revuelta del 16 de septiembre se transformaba en el día que cambiaba la historia. El manifiesto o proclama, ya por su sola datación celebrativa, significa que la nación visualizada por Hidalgo y Allende, en cuanto decidida a recobrar sus derechos, tenía una fecha de nacimiento. En realidad la proclama va más allá, puesto que en su mayor parte constituye el primer recuento de dos años de la gesta insurgente. Si bien en tono retórico, es la historia primigenia y resumida del movimiento. De esta manera, el 16 de septiembre aparece con una cauda de acontecimientos y de nuevos héroes. Su sentido era un estímulo para los propios insurgentes, esto es, los de las filas de Rayón, pero en especial lo era para los insurrectos de Huichapan, a fin de darles a conocer la visión de la cúpula insurgente, la presidida por un heredero directo e Hidalgo y de Allende, más allá de los objetivos localistas y de grupo de los Villagranes.

En la génesis del nuevo Estado Nación, por lo que respecta a su representación simbólica, la proclama o manifiesto de Rayón en Huichapan ocupa un lugar primordial, un año antes de los fastos de Chilpancingo. Tal vez por ello, al nuevo Estado de la federación que se creó en 1869 a partir de varios territorios, en que desde luego entraba la comarca de Huichapan, se le dio el nombre de Hidalgo. El prócer nunca pisó estas tierras, pero fue ahí donde por primera vez se rindió homenaje a la gesta por él iniciada.

Llama la atención la voluntad de Rayón de corroborar la memoria histórica patriótica, al celebrar con no menos solemnidad y alboroto festivo el onomástico de Hidalgo el 29 del mismo mes, también en Huichapan. El sermón de Velasco es el primer modelo para la tradición oratoria septembrina. La remembranza de episodios de la lucha es breve en comparación con la proclama del 16; en cambio, es más explícito en señalar penalidades y fracasos desde una perspectiva providencialista. Propio de esta pieza es la mitificación de Hidalgo y la sacralización del movimiento (Herrejón Peredo, 1995: 125-143).

Para interpretar mejor las celebraciones referidas, conviene tomar en cuenta algunos conceptos teóricos sobre conmemoraciones, recientemente expuestos y analizados por Susi Ramírez (Ramírez Peña, próximamente: 40-60). ${ }^{23}$ El fenómeno de las conmemoraciones es entendible a partir del concepto de imaginario social para de-

23 A pesar de la acotación temporal del título, el estudio retoma su asunto desde orígenes remotos y próximos en varias culturas. 
signar representaciones sociales encarnadas en instituciones. Las conmemoraciones nacionales y regionales de México sobre la independencia son un ejemplo, donde se pueden detectar cuatro características: una fuerza enunciativa en el origen mítico de su espacio imaginario conquistado, un imaginario emancipado, los próceres como héroes-santos y su imaginario progresista del tiempo. Todo esto representado material y de manera actancial y puesto en escena en espacio público, en un lenguaje unificador.

Para nuestro caso, no hallamos una representación actancial del espacio imaginario conquistado, pero tanto la proclama como el sermón, aunque no hablen de la conquista, presuponen ese espacio al referirse a la servidumbre padecida largo tiempo por el gobierno español despótico. El imaginario emancipado está presente en el carácter festivo de la celebración: las salvas, los adornos, la iluminación, la serenata, la música y, desde luego, en el optimismo de las piezas oratorias: triunfos por encima de las desgracias. A este optimismo se vincula el imaginario progresista del tiempo, por cuanto se espera el aumento de triunfos hasta la independencia definitiva, objetos implicados como esperanza en la mentalidad reinante y expresados con firmeza en las piezas oratorias. El imaginario de los próceres como héroes-santos aparece claramente en la proclama y en el sermón, y a no dudarlo, entraba desde antes de las celebraciones en la mentalidad de los soldados de Rayón y de Correa aleccionados al menos desde el mandato de los Elementos de llevar a cabo tales celebraciones; por lo que hace a los combatientes de Huichapan y a sus habitantes, había el fresco recuerdo de la celebración festiva que se hiciera ahí el 29 de octubre de 1810 por la captura del alcalde de corte Collado y otros funcionarios, según reseñamos. Comportó banderas tremoladas y Te Deum en la parroquia; sin duda con el reconocimiento a los insurgentes que habían protagonizado la captura, pero no más. Entra en la serie de festejos que tanto insurgentes como realistas hacían por sus victorias o entradas a una pobla- ción. Es otro género, no obstante algunos rasgos similares con las conmemoraciones.

Abunda Ramírez sobre la naturaleza de los actos cívicos, considerando que los imaginarios enunciados, si bien se encarnan y entrelazan con esos actos, se distinguen de ellos. Esos actos están imbricados en contenidos narrativos que pueden ser textuales, en sentido amplio, o bien narrados de manera argumentativa. Por lo mismo hay que atender a su representación narrativa, visual y actancial, donde aparecen la teatralidad, la monumentalidad y la textualidad. Y como se trata de conmemoraciones reiteradas por generaciones, entran en la categoría de tradiciones. En cuanto a la teatralidad, por ejemplo un desfile, aunque sea vivencial, tiene connotaciones de tradición que se reflejan en la jerarquía de los participantes, el orden procesional en que aparecen los símbolos patrios enunciados, los grupos. Respecto a la textualidad, tiene más capas de sedimentación como tradición. Sin perder movilidad, común a todas las configuraciones celebratorias, la textualidad participa en una cantidad de oportunidades enunciativas, que retoman cosas viejas y cosas nuevas, como de un cofre del tesoro. Otro sentido de tradición que va más allá del tipo de tradición a través de generaciones.

Varios de los actos cívicos de las conmemoraciones de Huichapan se enmarcan en categorías enunciadas por Ramírez, desde luego la teatralidad, como es patente por el traslado del Presidente de su casa a la iglesia y a las plazas con oficialidad y tropa abanderada, secretarios y otros, Quintana Roo entre ellos, no sin música luego de la Misa, acto religioso-cívico, así como disparos y salvas de artillería. La textualidad en sentido restringido de lenguaje o texto escrito, también es evidente por la proclama y el sermón. En cambio, la textualidad como narrativa actancial es todo el conjunto: lo dicho y el ámbito general festivo desarrollado gradualmente a través de ese tiempo corto, pero henchido de significado, con el repique de campanas al amanecer, la ornamentación de calles, su iluminación, la serenata y la participación del pueblo. La 
monumentalidad, entendida como la erección o colocación de estatuas, estelas, retratos, placas o inauguración de inmuebles nuevos o remodelados, no aparece. La interpretación de todo esto como tradición, merece explicación por nuestra parte. Primero, la fiesta es un sistema de tradiciones, donde cada elemento responde a sus tradiciones particulares. Segundo, la conmemoración como unidad es una tradición. Pero las conmemoraciones patrióticas de Huichapan como unidad son una excepción al concepto de tradición, porque carecen de reiteración antecedente, elemento esencial sin el cual no hay tradición (Herrejón Peredo, 1994: 135-149). Era la primera vez que se celebraba el Grito y el onomástico de Hidalgo. No se podía asegurar entonces con certeza que la celebración sería reiterativa. Sólo retrospectivamente, a partir del México independiente, el Grito entró a la categoría de tradición con el valor excepcional para Huichapan de ser el primer eslabón de una efectiva cadena. Por otra parte hemos señalado que si bien formalmente el contenido de la tradición, lo que se transmite, es distinto del acto y del medio de transmisión, ese mismo acto y medio son objeto de tradición. En este sentido, Ramírez trae a colación a Paul Connerton, quien señala la importancia de estudiar el acto en sí mismo, y no sólo el contenido que se representa, porque el acto performativo o puesta en escena -lo actuado, representado- es un ritual hecho significativo a través de algún tipo de lenguaje expresivo que proporciona valiosa información de los que lo realizan y de la sociedad que lo consume. En tal postura resalta la visión del acto conmemorativo como un acto vivo, presencial y hasta cierto punto polarizante desde las emociones y las sensaciones en el momento enunciativo, donde en apariencia el tiempo sacro sustituye al mundano (Connerton, 1989: 40-60). ${ }^{24}$

Finalizamos advirtiendo otra peculiaridad de las conmemoraciones de Huichapan: ocu-

24 El sentido performativo es sensorial y simbólico, va directamente relacionado con el acto solemne que evoca o atrae al observador a sentir implicación emotiva con el mencionado acto. rren dentro de la misma guerra que se celebra, cuyo promotor había sido compañero de los iniciadores de la gesta y estaba ahí; guerra que ofrecía complejas facetas según combatientes y posibilidades: guerra al estilo partisano, no sin resabios de guerra civil, rebelión de intereses locales, y guerra formal de independencia nacional con los avatares y propósitos de una revolución.

\section{Fuentes consultadas}

AGN (Archivo General de la Nación), Indiferente virreinal. Operaciones de Guerra.

Alamán, Lucas (1968), Historia de México, México, Jus.

Biblioteca Nacional de México, Fondo José María Lafragua.

Bustamante, Carlos María de (1961), Cuadro Histórico de la Revolución Mexicana, México, Comisión Nacional para la celebración del sesquicentenario de la proclamación de la Independencia nacional y del cincuentenario de la Revolución Mexicana.

Cadena Guerrero, Antonio (1996), Fuentes para la biografía del bachiller José Manuel Correa, cura independentista de Nopala, México, Gobierno del Estado de Hidalgo.

Carreño, Alberto María (1963), Efemérides de la Real y Pontificia Universidad de México, Ciudad de México, UNAM.

Connerton, Paul (1989), How Societies remember, Cambrigde, Cambrigde University Press.

Fernández de Recas, Guillermo S. (1963), Grados de licenciados, maestros y doctores en artes, leyes, teología y todas facultades de la Real y Pontificia Universidad de México, Ciudad de México, UNAM.

Gaceta del gobierno de México (1812), Ciudad de México, martes 27 de octubre, III, núm. 307. 
García, Genaro (1910), Documentos Históricos Mexicanos, Ciudad de México, Museo Nacional de Arqueología, Historia y Etnología.

García Díaz, Tarsicio (1971), "La Prensa Insurgente", pp. 577-592, en Manuel Calvillo (coord.), La República Federal Mexicana. Gestación y Nacimiento, t. V, Ciudad de México, Departamento del Distrito Federal.

Garritz Ruiz, Amaya (1990), Impresos novohispanos 1808-1821 (coordinación de Virginia Guedea y colaboración de Teresa Lozano), Ciudad de México, UNAM, 1990.

González Obregón, Luis (1966), México viejo, Ciudad de México, Patria.

Guardino, Peter F. (2001), Campesinos y política en la formación del Estado Nacional de México. Guerrero, 1800-1857, Ciudad de México, Gobierno del Estado de Guerrero.

Guedea, Virginia (1995), Prontuario de los insurgentes, Ciudad de México, UNAM-Centro de Estudios de la Universidad/Instituto de Investigaciones Dr. José Luis Mora.

Guedea, Virginia (1992), En busca de un gobierno alterno: los Guadalupes de México, Ciudad de México, UNAM.

Guerra, José (Fray Servando Teresa de Mier) (1813), Historia de la revolución de Nueva España, Londres, Guillermo Glindon.

Guerrero Magos, Gaspar y Guerrero Trejo, Leopoldo (1972), "Sitios históricos y monumentos arquitectónicos", en Conozca Huichapan, México.

Guzmán Pérez, Moisés (2007), "Presentación”, en Moisés Guzmán Pérez (coord.), Guerra e imaginarios políticos en la época de las independencias, Morelia, Universidad Michoacana de San Nicolás de Hidalgo.

Hamnett, Brian R. (1990), Raíces de la insurgencia en México. Historia regional 1750-1824, Ciudad de México, Fondo de Cultura Económica.
Hernández y Dávalos, J.E. (1877), Colección de documentos para la historia de la guerra de independencia de México, Ciudad de México, José María Sandoval, Impresor.

Herrejón Peredo, Carlos (1995), "Les origines du discours civique mexicain", Cahiers du Centre de Recherches Historiques, núms. 14/15, abril-octubre, París, École des Hautes Etudes en Sciences Sociales, pp. 125-143.

Herrejón Peredo, Carlos (1994), "Tradición. Esbozo de algunos conceptos", Relaciones. Estudios de Historia y Sociedad, núm. 59, Zamora, El Colegio de Michoacán, pp. 135-149.

Herrejón Peredo, Carlos (1987), Morelos. Documentos inéditos de vida revolucionaria, Zamora, El Colegio de Michoacán.

Landavazo, Marco Antonio (2009), "Para una historia social de la violencia insurgente: el odio al gachupín", Historia Mexicana, 59 (1), Ciudad de México, El Colegio de México.

Landavazo, Marco Antonio (2005), "De la razón moral a razón de Estado: violencia y poder en la insurgencia mexicana", Historia Mexicana, 54 (3), Ciudad de México, El Colegio de México, pp. 833-865.

Lemoine, Ernesto (1980), "Sobre los fondos del AGNM referentes a la Revolución de 1810. Documentos sobre la Revolución de 1810", Boletín del Archivo General de la Nación, julio-septiembre, t. IV, núm. 3 (13), Ciudad de México, pp. 22-27.

Lemoine, Ernesto (1965), Morelos, su vida revolucionaria a través de sus escritos y otros testimonios de la época, Ciudad de México, UNAM.

Lempérière, Annick (2004), "Revolución, guerra civil, guerra de independencia en el mundo hispánico 1808-1825", Ayer, 3 (55), Madrid, Asociación de Historia Contemporánea/Marcial Pons, Ediciones de Historia, pp. 15-36. 
Miquel i Vergés, José María (1969), Diccionario de insurgentes, Ciudad de México, Porrúa.

Miquel i Vergés, José María (1941), La independencia mexicana y la prensa insurgente, Ciudad de México, El Colegio de México.

Ortiz Escamilla, Juan (1997), Guerra y gobierno. Los pueblos y la Independencia de México, Sevilla, Universidad de Sevilla/Universidad Internacional de Andalucía/El Colegio de México/Instituto Mora.

Pérez Vejo, Tomás (2012), "Las guerras de Independencia como guerras civiles: un replanteamiento del nacimiento de la modernidad política en Hispanoamérica", en Carlos Alberto Patiño Villa (ed.), Estado, guerras internacionales e idearios políticos en Iberoamérica, Bogotá, Universidad Nacional de Colombia.

Ramírez Peña, Susi W. (próximamente), "El Occidente de México y sus imaginarios de nación. Conmemoraciones, héroes y monumentos en 1910, 1921 y 1960", tesis doctoral, Centro de Estudios de las Tradiciones de El Colegio de Michoacán.

Rublúo, Luis (1967), "Poesía conmemorativa de la Independencia de México", Boletín Bibliográfico de la Secretaría de Hacienda y Crédito Público, Suplemento, 15 de septiembre, núm. 375, Ciudad de México, Secretaría de Hacienda y Crédito Público, pp. 4-9.

Schmitt, Carl (2013), Teoría del partisano. Acotación al concepto de lo político, Madrid, Trotta.

SEP (Secretaría de Educación Pública) (1985), Diario de gobierno y operaciones militares de la secretaría y ejército al mando del Exmo. Sr. Presidente de la Suprema Junta y ministro universal de la Nación, Lic. Don Ignacio López Rayón, en La Independencia según lgnacio Rayón, Ciudad de México, Secretaría de Educación Pública.
SEP (Secretaría de Educación Pública) (1927), Morelos. Documentos inéditos y poco conocidos, Ciudad de México, Secretaría de Educación Pública.

Van Young, Eric (2006), La otra rebelión. La lucha por la independencia de México, 1810-1821, Ciudad de México, Fondo de Cultura Económica.

Velasco, Francisco Lorenzo de (1812), Sermón que en el cumpleaños del serenísimo señor don Miguel Hidalgo y Costilla, primer héroe de la patria, dijo [...]. Tlalpujahua, Imprenta Nacional de América.

Villaseñor y Villaseñor, Alejandro (1963), Biografías de los héroes y caudillos de la Independencia, Ciudad de México, Jus.

Recibido: 13 diciembre de 2020. Reenviado: 3 de mayo de 2021. Aceptado: 21 junio de 2021.

\section{Carlos Herrejón Peredo}

Doctor en Historia por la Escuela de Altos Estudios en Ciencias Sociales, París, y licenciado en Teología por la Universidad Gregoriana de Roma. Es miembro del Sistema Nacional de Investigadores (SNI), nivel III. Sus líneas de investigación son: lengua, textos y tradición (Tradiciones en la Insurgencia: Congreso, Constitución, Poder Judicial), así como religión y cultura (Michoacán: tradición religiosa, 1821-1910). Entre sus publicaciones más recientes destacan, como autor: "Documento. La visita ad limina de Clemente Munguía sobre el obispado de Michoacán. 1862", Relaciones. Estudios de Historia y Sociedad, núm. 148, Zamora, El Colegio de Michoacán, pp. 185-200 (2016) y "El Congreso Constitucional de la insurgencia 1814-1815”, Estudios de Historia Moderna y Contemporánea de México, núm. 51, Ciudad de México, Instituto de Investigaciones Históricas de la Universidad Nacional Autónoma de México, pp. 1-18 (2016). 


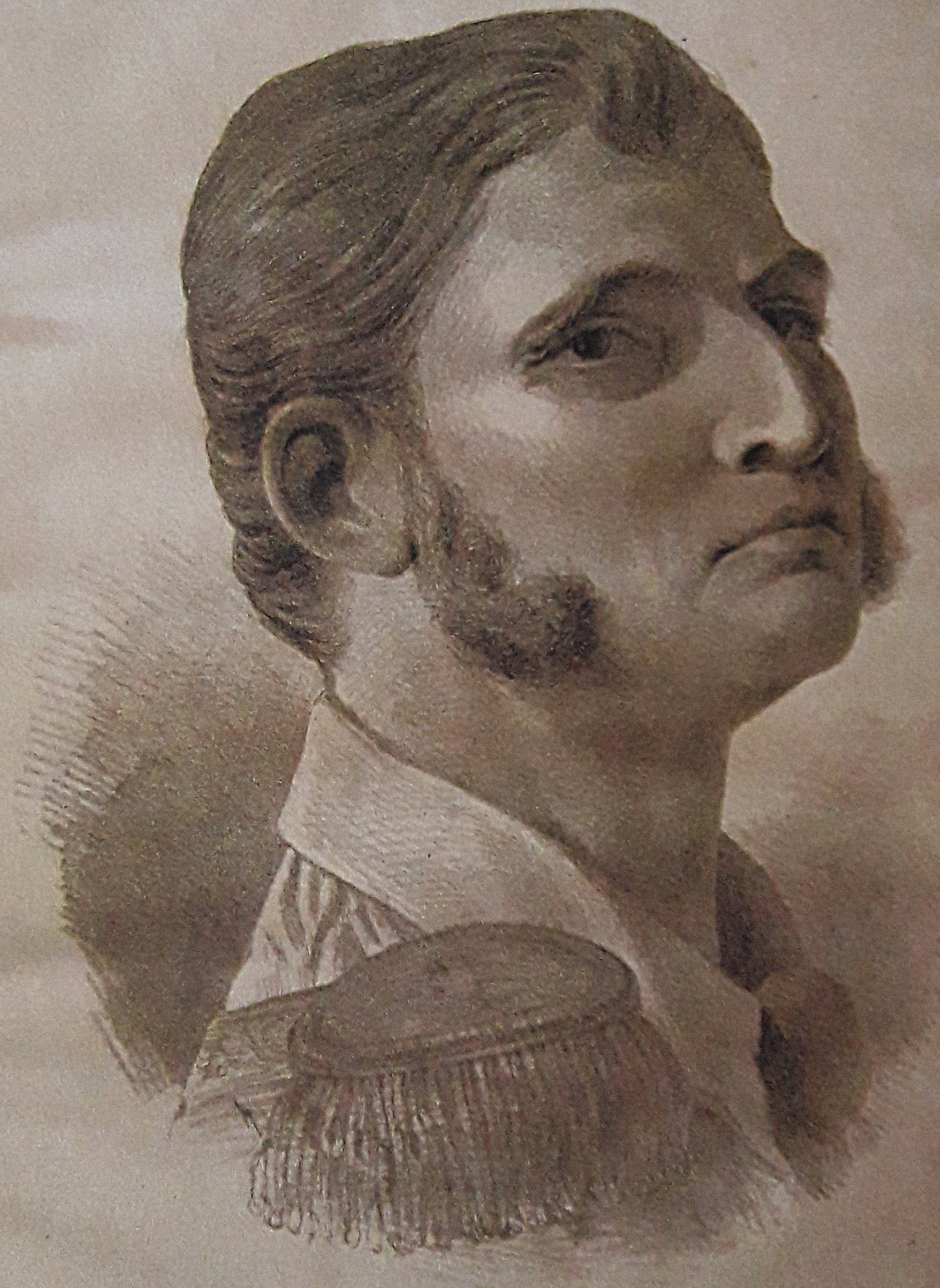

